\title{
Nanomedical Relevance of the Intermolecular Interaction Dynamics-Examples from Lysozymes and Insulins
}

Ruiyan Zhang, ${ }^{\dagger, \ddagger}$ Ning Zhang, $^{\dagger}$ Marzieh Mohri, ${ }^{\ddagger}$ Lisha Wu, ${ }^{\|}$Thomas Eckert, $^{\perp, \#}{ }^{\text {Vadim B. Krylov, }}{ }^{\nabla}$ Andrea Antosova, $\bigcirc$ Slavomira Ponikova, ${ }^{\bigcirc}$ Zuzana Bednarikova, $\bigcirc$ Philipp Markart,, $\mathbb{I}$ Andreas Günther, ${ }^{\circledR}$ Bengt Norden, ${ }^{\|}$Martin Billeter, ${ }^{\bowtie}$ Roland Schauer, ${ }^{\bowtie}$ Axel J. Scheidig, ${ }^{\S}$ Bhisma N. Ratha, ${ }^{z}$ Anirban Bhunia, ${ }^{\circledR \odot}$ Karsten Hesse, ${ }^{\bullet}$ Mushira Abdelaziz Enani, ${ }^{\alpha}$ Jürgen Steinmeyer, Athanasios K. Petridis, ${ }^{\bigcirc}$ Tibor Kozar, ${ }^{\top}$ Zuzana Gazova, ${ }^{\circledR}$ Nikolay E. Nifantiev, and Hans-Christian Siebert**

${ }^{\dagger}$ Institute of Biopharmaceutical Research, Liaocheng University, Liaocheng 252059, P. R. China

${ }^{*}$ RI-B-NT Research Institute of Bioinformatics and Nanotechnology, Franziusallee 177, 24148 Kiel, Germany

${ }^{\S}$ Institute of Zoology, Department of Structural Biology, Christian-Albrechts-University, Am Botanischen Garten 1-9, 24118 Kiel, Germany

"Department of Chemical and Biological Engineering, Chalmers University of Technology, 41296 Gothenburg, Sweden

${ }^{\perp}$ Department of Chemistry and Biology, University of Applied Sciences Fresenius, Limburger Str. 2, 65510 Idstein, Germany

${ }^{\#}$ Institut für Veterinärphysiolgie und Biochemie, Fachbereich Veterinärmedizin, Justus-Liebig-Universität Gießen, Frankfurter Str. 100, 35392 Gießen, Germany

${ }^{\nabla}$ Laboratory of Glycoconjugate Chemistry, N.D. Zelinsky Institute of Organic Chemistry, Russian Academy of Sciences, Leninsky prospect 47, 119991 Moscow, Russian Federation

ODepartment of Biophysics Institute of Experimental Physics, Slovak Academy of Sciences, Watsonova 47, 04001 Kosice, Slovakia

Medical Clinic II, Justus-Liebig-University, Klinikstraße 33, 35392 Giessen, Germany

${ }^{\text {II }}$ Pneumology, Heart-Thorax-Center Fulda, Pacelliallee 4, 36043 Fulda, Germany

${ }^{\bowtie}$ Department of Chemistry and Molecular Biology, University of Gothenburg, 40530 Gothenburg, Sweden

Institute of Biochemistry, Christian-Albrechts-University, Olshausenstrasse 40, 24098 Kiel, Germany

${ }^{8}$ Biomolecular NMR and Drug Design Laboratory, Department of Biophysics, Bose Institute, P-1/12 CIT Scheme VII (M), 700054 Kolkata, India

-Tierarztpraxis Dr. Karsten Hesse, Rathausstraße 16, 35460 Stauffenberg, Germany

${ }^{\mathrm{x}}$ Infectious Diseases Division, Department of Medicine, King Fahad Medical City, P.O. Box 59046, 11525 Riyadh, Kingdom of Saudi Arabia

Laboratory for Experimental Orthopaedics, Department of Orthopaedics, Justus-Liebig-University, Paul-Meimberg-Str. 3, D-35392 Giessen, Germany

${ }^{\circ}$ Neurochirurgische Klinik, Universität Düsseldorf, Geb. 11.54, Moorenstraße 5, 40255 Düsseldorf, Germany

Center for Interdisciplinary Biosciences, TIP-UPJS, Jesenna 5, 04001 Kosice, Slovakia

Supporting Information

ABSTRACT: Insulin and lysozyme share the common features of being prone to aggregate and having biomedical importance. Encapsulating lysozyme and insulin in micellar nanoparticles probably would prevent aggregation and facilitate oral drug delivery. Despite the vivid structural knowledge of lysozyme and insulin, the environment-dependent oligomerization (dimer, trimer, and multimer) and associated structural dynamics remain elusive. The knowledge of the intra- and intermolecular interaction profiles has cardinal importance for the design of encapsulation protocols. We continued...

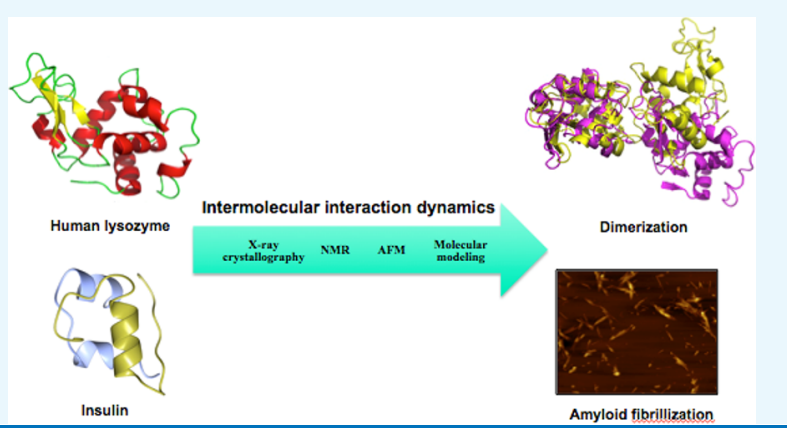

Received: September 21, 2018

Accepted: November 28, 2018

Published: February 27, 2019 
have employed various biophysical methods such as NMR spectroscopy, X-ray crystallography, Thioflavin T fluorescence, and atomic force microscopy in conjugation with molecular modeling to improve the understanding of interaction dynamics during homo-oligomerization of lysozyme (human and hen egg) and insulin (porcine, human, and glargine). The results obtained depict the atomistic intra- and intermolecular interaction details of the homo-oligomerization and confirm the propensity to form fibrils. Taken together, the data accumulated and knowledge gained will further facilitate nanoparticle design and production with insulin or lysozyme-related protein encapsulation.

\section{INTRODUCTION}

Several natural and synthetic proteins of pharmacological importance (including, but not limited to, lysozyme and insulin) are prone to aggregation into insoluble polymeric fibrils, a biologically and industrially unwanted feature. To extend the long-term usability of pharmacologically significant proteins, their inactivation caused by unfolding and/or aggregation needs to be minimized. As lysozyme and insulin are well-established protein drugs, these can serve as model components to study conditions that could help stabilize proteins and prevent them from aggregation. Formation of lysozyme (muramidase) ${ }^{1-3}$ or insulin complexes ${ }^{4-6}$ into higher aggregates or fibrils, but also their occurrence in native states, needs to be studied by a combination of biochemical and biophysical techniques to shed light into the mechanism of amyloid formation. Protein misfolding and consequent aggregation are associated with more than 20 diseases. $^{7}$ Although a significant amount of work has been conducted to study the amyloid-related problems of living organisms, neither the mechanisms of fibril creation nor some ways of their disruption are fully understood yet. What is assumed nowadays is that inter- and intramolecular interactions could play the decisive role for amyloidogenic processes. Both insulin and lysozyme belong to the group of amyloidogenic proteins. There are currently several commercial variations of insulin available: synthetic human insulin (e.g., Actrapid, Lispro), porcine insulin (Caninsulin), and glargine insulins (Lantus, Abasaglar, Glaritus, and Basalog) in which one amino acid is replaced and two Arg residues are added. Beside these variations, in the case of the glargine insulins, different expression vectors (Escherichia coli for Lantus and Abasaglar, and yeast for Glaritus and Basalog) are used and lead to minor conformational differences. This fact has to be carefully considered when insulin structural data sets are compared. Variations in the production and formulation processes can be correlated with alterations in structure and dynamics of the proteins under study. Glycosylation impurities have been described for the glargine insulins (Glaritus and Basalog) that are expressed in yeasts. ${ }^{4-6,8}$ Such kind of glycosylation that does not occur in standard insulins may influence their structural properties, for example, the aggregation behavior of these glargine biosimilars, but could also enhance their lifetime as it is in the case of naturally occurring glycosylated hormones such as erythropoietin. ${ }^{9}$ However, this kind of insulin glycosylation has to be considered as impurity since it does not occur at all in glargine insulin (Glaritus and Basalog) molecules in a homogenous way. Glargine insulin is a human insulin analog, with three amino acid difference. In the A-chain of glargine insulin, Asn at position 21 is mutated to Gly. In the B-chain of glargine insulin, two Arg residues at positions 31 and 32 are added. Recently, Hermanns et al. ${ }^{10}$ discussed the clinical impact of such modifications on diabetes therapies. In the synthetic insulin Lispro (marketed by Eli Lilly as Humalog), the penultimate lysine and proline residues on the C-terminal end of the B-chain are reversed in comparison to human insulin. This small modification in the primary sequence does not influence the receptor binding but blocks the formation of dimers and hexamers. ${ }^{11,12}$ This has a significant impact on bioavailability since Lispro is active immediately. In comparison to our biophysical studies on insulin variants (human or porcine insulin vs the long-acting synthetic glargine insulin Lantus, Abasaglar, Glaritus, or Basalog), the corresponding physical parameters for larger proteins with similar clinical relevance, that is, lysozyme (here human lysozyme (HL) and hen egg white lysozyme (HEWL)), could be obtained.

Lysozyme has been used for years as a model for amyloid aggregation. ${ }^{13}$ Recently, we have reported the ability of lysozymes to specifically bind certain sections from the carbohydrate part of lipopolysaccharide (LPS) from Klebsiella pneumoniae. ${ }^{14}$ Nonionic detergents can also easily interact with amino acids of the amyloidogenic region of HEWL of the lysozyme, ${ }^{15}$ affecting thus the amyloid fibrillization that can also be inhibited by phospholipids. ${ }^{16}$ Furthermore, the effects of detergents $^{17}$ and natural products ${ }^{18,19}$ on insulin and lysozyme aggregation and lysozyme and insulin antiamyloid structurefunction screening of small libraries ${ }^{20}$ have been reported recently.

Analysis of the corresponding intermolecular interactions is of importance also for the design of target-directed nanoparticles because the carbohydrate recognition part of the protein can be regarded as an intrinsic anchor unit for cell-surface-exposed contact structures. The surface properties (e.g., the electrostatic surface potentials) of the two lysozymes under study (HL and HEWL) due to several variances in the amino acid sequences differ from each other. These differences can be correlated with the aggregation/fibrillization behavior of the two lysozyme species-HL and HEWL. It has to be emphasized that for both classes of biomolecules (insulins and lysozymes), new data with respect to the aggregation dynamics can be achieved when the arsenal of biophysical techniques is applied in a way that all processes on the submolecular and in the case of ion involvement are considered. Similar to the aggregation behavior of glargine insulins also in the case of the lysozymes under study Arg residues and the corresponding charges play a crucial role in both dimer and multimer formations. Knowledge about all crucial details in relation to the structural stability under different physical and chemical conditions is essential for the optimal clinical application of encapsulated protein drugs. In the case of the encapsulation of small organic compounds that are used, for example, as antipsychotic drugs, it is of relevance to analyze their structural behavior at a high precision level using ab initio calculations. ${ }^{21-23}$ The requirements to utilize quantum chemical approaches relate to hindered rotations in partial double bonds that are often occurring in medications that are used as therapeutics against schizophrenia and other psychotic diseases. ${ }^{24}$ Also in the case of larger drugs, one has to proceed in a similar way when these compounds have to be encapsulated in target-directed nanoparticles. ${ }^{25-27}$ Accordingly, we centered our attention on studies of the structure, aggregation, and intermolecular interaction profiles of these proteins and on 
Table 1. Different Crystal Forms of Human Lysozyme under Different Crystallization Conditions

\begin{tabular}{|c|c|c|c|c|c|c|c|c|}
\hline \multirow[b]{3}{*}{ crystal ID } & \multicolumn{3}{|c|}{ crystallization condition } & \multicolumn{3}{|c|}{ unit cell dimension } & \multirow[b]{3}{*}{ space group } & \multirow[b]{3}{*}{ subunit number/asymmeric unit } \\
\hline & & & & $a$ & $b$ & $c(\AA)$ & & \\
\hline & $\mathrm{pH}$ & buffer & temperature $(\mathrm{K})$ & $\alpha$ & $\beta$ & $\gamma$ & & \\
\hline \multirow[t]{2}{*}{ Hlys \#1 } & 4.4 & $25 \mathrm{mM} \mathrm{NaOAc}$ & 291 & 33.22 & 56.12 & 60.95 & $P 212121$ & 1 \\
\hline & & $0.8 \mathrm{M} \mathrm{NaCl}$ & & 90.00 & 90.00 & 90.00 & & \\
\hline \multirow[t]{2}{*}{ Hlys \#2 } & 5.8 & $50 \mathrm{mM} \mathrm{Na}$ citrate & 291 & 42.84 & 63.93 & 109.81 & $P 212121$ & 2 \\
\hline & & $0.8 \mathrm{M} \mathrm{NaCl}$ & & 90.00 & 90.00 & 90.00 & & \\
\hline \multirow[t]{2}{*}{ ref \#1 (PBD:1LZS) } & 4.0 & $30 \mathrm{mM}$ sodium phosphate & 277 & 32.53 & 46.99 & 162.25 & $P 212121$ & 2 \\
\hline & & $1.8 \mathrm{M} \mathrm{NaCl}$ & & 90.00 & 90.00 & 90.00 & & \\
\hline \multirow[t]{2}{*}{ ref \#2 (PBD:1LZR) } & 6.0 & $30 \mathrm{mM}$ sodium phosphate & 286 & 34.01 & 56.51 & 60.91 & $P 212121$ & 1 \\
\hline & & $2.5 \mathrm{M} \mathrm{NaCl}$ & & 90.00 & 90.00 & 90.00 & & \\
\hline
\end{tabular}

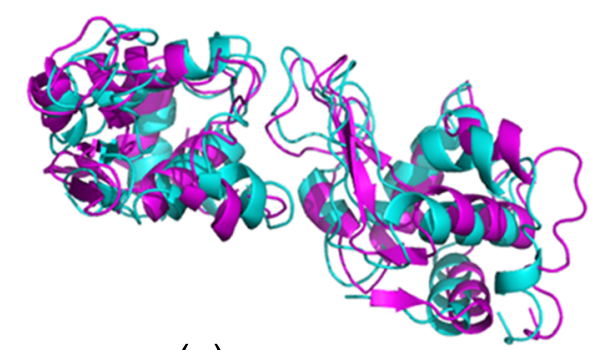

(a)

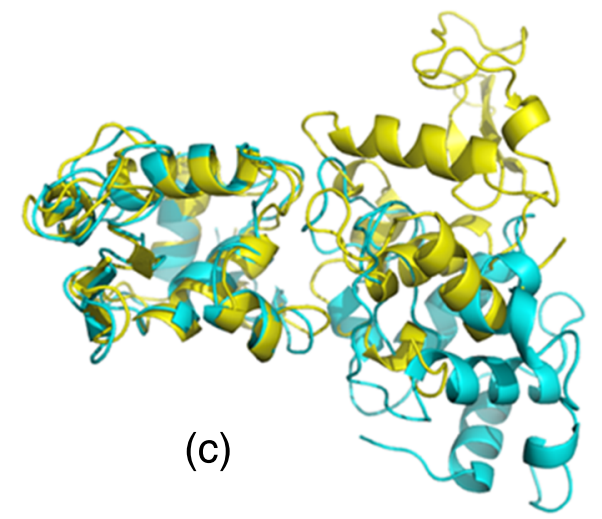

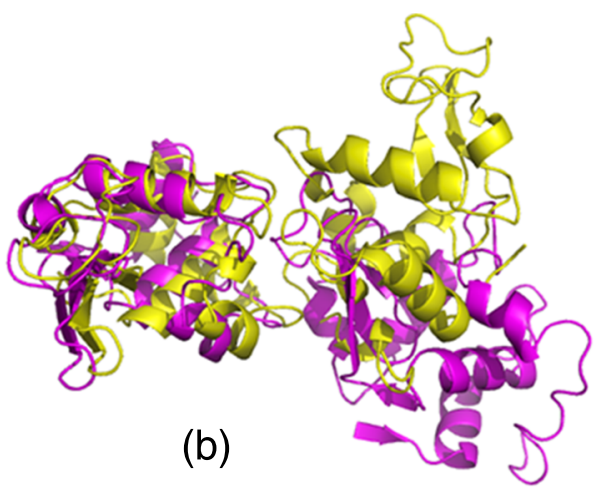

(b)

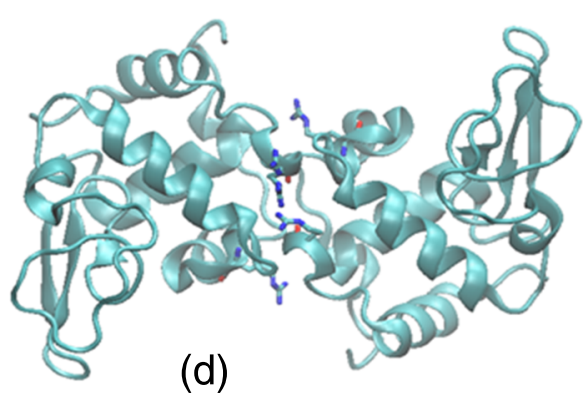

Figure 1. Superposition of (a) HL structure from molecular modeling (modeled dimeric arrangement, cyan) and crystal structure of HL, crystallized at $\mathrm{pH} 4$ (obtained from PDB-1lzs.pdb; ${ }^{32}$ purple). (b) Homodimeric model structure of HL, crystallized at a pH value of 5.8 (yellow) and the 1lzs.pdb - crystal structure (purple). (c) Homodimeric model structure of HL (yellow) and modeled dimeric arrangement of HL (cyan). (d) Crucial arginine residues at the interfaces of both monomers (Arg21, Arg107) are highlighted by a licorice presentation.

possibilities to encapsulate them into lipid nanoparticle carriers. In the case of an effective oral peptide/protein drug delivery, it is essential that so-called absorption enhancers enable an efficient transfer from the gastrointestinal tract to the bloodstream. Therefore, the drug-containing nanoparticles and the target cell in the intestine have to interact in a specific way. As the target molecules of these nanoparticles, cell-surface-exposed carbohydrate structures such as sialic acids ${ }^{14,27-31}$ will be our main focus. We selected insulin and lysozyme as two wellcharacterized proteins in combination with a set of biophysical techniques to perform an exemplary study for protein stability and optional forms of drug delivery.

\section{RESULTS AND DISCUSSION}

X-ray Crystallography Assay and Molecular Modeling Analysis. By variation of crystallization conditions for the structure determination of HL in complex with a tetrasacchar- ide, ${ }^{14}$ we have obtained crystals of $\mathrm{HL}$ with one lysozyme molecule per asymmetric unit (monomeric form) and crystals with two lysozyme molecules per asymmetric unit (dimeric form), as shown in Table 1 (Hlys \#1 and Hlys \#2, respectively). The arrangement of the two lysozyme molecules within this dimeric form differs significantly from the dimeric arrangement as predicted based on monomeric lysozyme by molecular modeling approaches as described before (Figure $1 \mathrm{a}-\mathrm{c}$ ). In addition, we have not found further evidence for these in silico results when human lysozyme has been analyzed with NMR methods at different $\mathrm{pH}$ values since monomers seem to be the preferred state.

Ten different insulin clusters resulted from Haddock 2.2 dimer simulation. Energy optimization was carried out on all of these dimers using the Hyperchem 8.0 program to assess the energetically most favorable structure. Table 2 summarizes the results from this minimization. 
Table 2. Hyperchem Energy Evaluation of the Insulin Dimeric Clusters

$\begin{array}{cc}\text { cluster } & \text { energy in } \mathrm{kcal} / \mathrm{mol} \\ 1 & 1467.3 \\ 2 & 1478.6 \\ 3 & 1481.0 \\ 4 & 1481.7 \\ 5 & 1488.1 \\ 6 & 1491.7 \\ 7 & 1493.0 \\ 8 & 1500.2 \\ 9 & 1502.9 \\ 10 & 1506.7\end{array}$

Protein dimer 1 corresponds to the crystal structure 1lzs.pdb. The other dimeric structures exhibit only a few $\mathrm{kcal} / \mathrm{mol}$ higher energy. Molecular dynamics (MD) simulations were performed to evaluate the possible existence of the dimeric forms under physiological conditions. Protein dimer 1 as well as the protein dimer from the crystal structure 1lzs.pdb were stable at $\mathrm{pH}=7.4$ at $298 \mathrm{~K}$ in physiological saline solution for $10 \mathrm{~ns}$ and showed only little fluctuations during the simulation. Accordingly, we can assume that the human lysozyme may exist in dimeric form under physiological conditions.

In the case of the insulins under study (human insulin, Actrapid/Lispro; porcine insulin, Caninsulin; and the synthetic long-acting glargine insulins), higher aggregates were not detected by NMR under the chosen measurement conditions. However, structural data sets based on X-ray or neutron diffraction experiments are available in the protein data bank: 3w7y.pdb, 1mso.pdb, and 3fhp.pdb.

Thioflavin T (ThT) Fluorescence Assay and Atomic Force Microscopy (AFM) Analysis. Comparing fibril formations of HL and HEWL using ThT assay, significant differences were observed in kinetics of fibrillization and amount of amyloid fibril aggregates (Figure 2). The time dependences of amyloid fibril formation determined for hen (red circles,

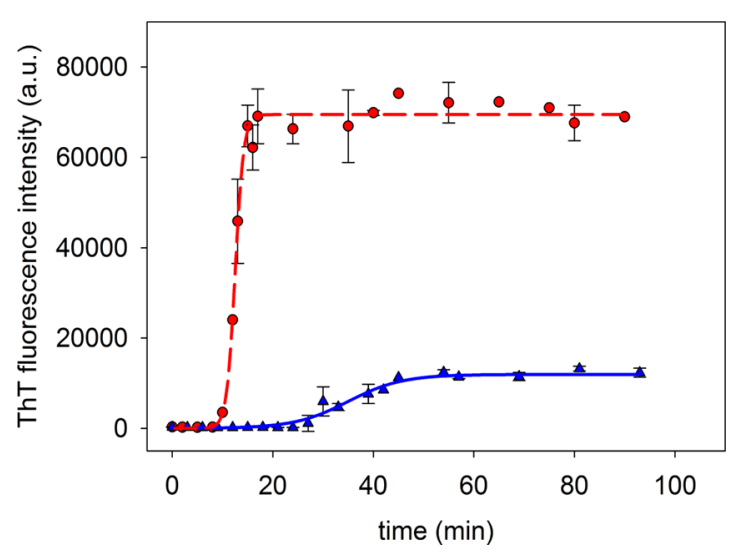

Figure 2. Time dependences of amyloid fibril formation determined for hen egg white (red circles) and human (blue triangles) lysozyme (10 $\mu \mathrm{M})$. The aliquots were selected at given time intervals, and the extent of lysozyme fibrillization was monitored by Thioflavin T (ThT) fluorescence assay $(20 \mu \mathrm{M}, \mathrm{ThT})$. The error bars represent the average deviation for repeated measurements of three separate samples. The curves were obtained by fitting of the average values by a nonlinear least-square method using Sigmoidal curve-parameter 4 in SigmaPlot software. The times of about $50 \mathrm{~min}$ (HL) and $20 \mathrm{~min}$ (HEWL) correspond to the plateau for the fluorescence intensities.
HEWL) and human (blue triangles, HL) lysozymes (10 $\mu \mathrm{M})$ differ in the lag phase, slope of the elongation phase, and value of plateau phase corresponding to the fibril mass. The formation of non-native states of lysozyme required for amyloid fibrillization that is occurring during lag phase was significantly prolonged in the case of human lysozyme with lag phase about $28 \mathrm{~min}$. Hen egg white lysozyme form these species under $10 \mathrm{~min}$. The overall time for formation of mature fibrils was also different-about 50 min for HL and $20 \mathrm{~min}$ for HEWL to achieve plateau for the fluorescence intensities. The observed kinetic characteristics of HL and HEWL fibrillization are summarized in Table 3. The lower fluorescence intensities of the plateau phase $(10000 \mathrm{au})$ for HL compare to HEWL (70 $000 \mathrm{au}$ ), suggesting formation of a lower amount of fibrillar structure or their association to bigger clusters.

Atomic Force Microscopy (AFM) is an important technique for visualization of amyloid aggregates. The obtained AFM images of lysozyme aggregates (Figure $3 \mathrm{a}, \mathrm{b}$ ) confirmed the ThT results.

These two complementary methods were also used for a detailed analysis of insulin fibril formation. Differences between fibril formation of human insulin and glargine insulin using ThT assay are still detectable (Figure 4) but not so obvious as in the case of lysozymes (Figure 2). Fibril formation of both types of insulin follows the nucleation polymerization model. The modified amino acid chain of the glargine insulin does not lead to stronger alterations when comparing glargine with human insulin during the fibril-formation process; however, insulin Basalog (blue triangles) has a longer lag phase (4.5 min) when compared to human insulin $t_{\text {lag }}$ equal to $1.5 \mathrm{~min}$ (green triangles). The differences in other kinetic parameters $\left(t_{1 / 2}\right.$, $t_{\text {plateau }}$ and $\left.I_{\text {fluo }} \max \right)$ are not so significant and are presented in Table 3.

After $2 \mathrm{~h}$, the morphologies of human insulin and glargine insulin fibrils visualized using the AFM technique show small but characteristic differences (Figure 5a,b). Glargine insulin (Figure $5 b$ ) forms unbranched fibrils that are thinner than fibrils of human insulin (Figure 5a).

Next, we tested with NMR methods whether critical parameters of the insulins and lysozyme for further structural comparison can be obtained under physiological conditions.

NMR Results-Analyses of Human, Porcine, and Glargine Insulins as well as Human Lysozyme from Transgenic Cow. We have found that it is possible to record NMR spectra of insulin drugs taken directly from the injection pen (Figure 6a,b). Large excipient signals were detected, but they do not disturb our structural analysis of the compounds itself in a significant way. The two one-dimensional (1D) NMR spectra Figure 6a (top, bottom) show Abasaglar glargine probes from two different charges, which were stored in a slightly different way. One probe was stored permanently in the refrigerator; the other one was stored for one night outside the refrigerator at room temperature. The $1 \mathrm{D}$ spectra of the two probes are completely identical and can therefore not be discriminated although the injection pens have been treated under different cooling conditions. Also in the corresponding nuclear Overhauser enhancement (NOESY) spectra (Figure $6 \mathrm{~b})$, no differences were detected. It turned out that especially the NOESY spectra of Abasaglar glargine insulin can be evaluated despite the strong excipient signals in a sufficient way.

Contrary to the Abasaglar insulin probes that were taken directly from the injection pen, all signals of the human lysozyme extracted from the milk of transgenic cow belong to the protein 
Table 3. Kinetic Parameters of Insulin and Lysozyme Amyloid Fibrillization

\begin{tabular}{|c|c|c|c|c|}
\hline kinetic parameters & HL & HEWL & human insulin & glargine insulin \\
\hline lag-time $\left(t_{\text {lag }}\right)(\mathrm{min})$ & $28 \pm 0.4$ & $10 \pm 0.3$ & $1.5 \pm 0.1$ & $4.5 \pm 0.2$ \\
\hline half-time $\left(t_{1 / 2}\right)(\mathrm{min})$ & $29 \pm 0.6$ & $13 \pm 0.2$ & $6.2 \pm 0.3$ & $8.2 \pm 0.2$ \\
\hline$I_{\text {fluo }} \max (\mathrm{au})$ & $10000 \pm 100$ & $70000 \pm 200$ & $47000 \pm 150$ & $55000 \pm 200$ \\
\hline$t_{\text {plateau }}(\min )$ & $50 \pm 0.2$ & $20 \pm 0.1$ & $6.8 \pm 0.2$ & $11.4 \pm 0.6$ \\
\hline
\end{tabular}

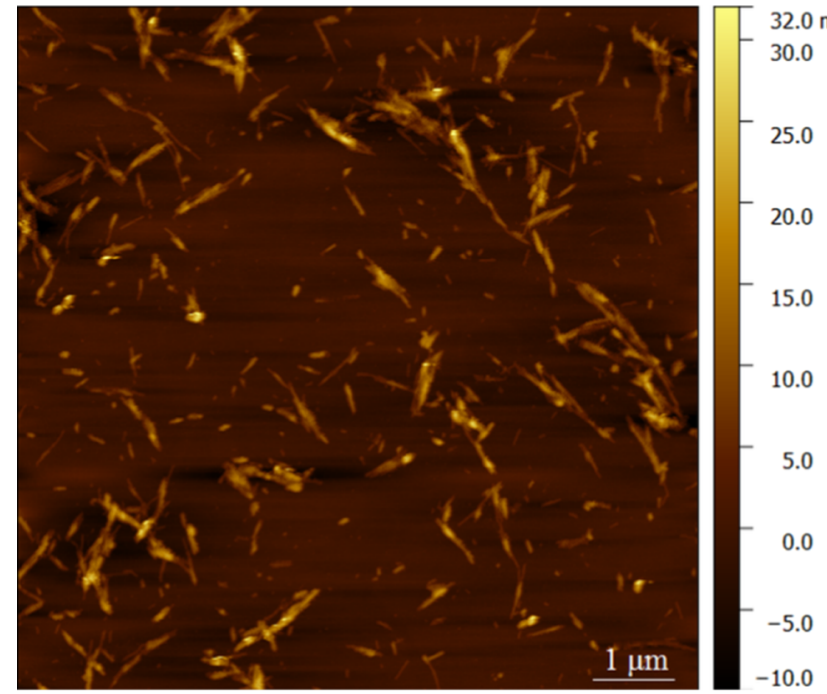

(a)

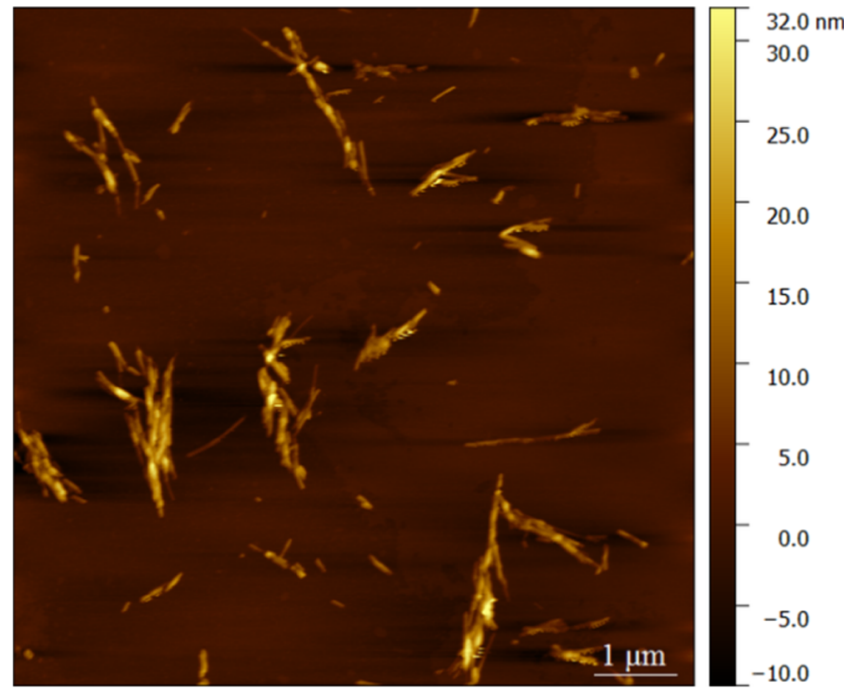

(b)

Figure 3. AFM images of (a) human lysozyme (HL) and (b) hen egg white lysozyme (HEWL) amyloid fibrils confirm the (ThT) fluorescence assay results by another biophysical technique in an independent way.

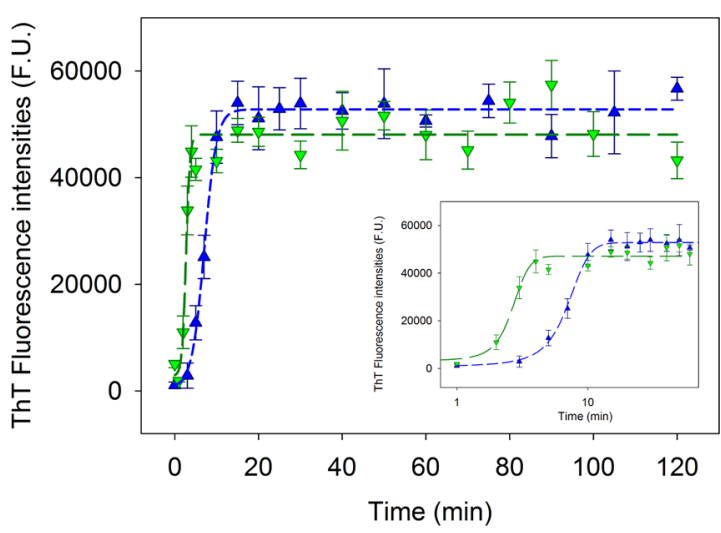

Figure 4. Time dependences of amyloid fibril formation determined for glargine insulin Basalog (blue triangles) and human insulin (green triangles) $(10 \mu \mathrm{M})$. Left side, complete time period. Inset, time period of fibril formation between 1 and $15 \mathrm{~min}$. The data were fitted with sigmoidal curve-parameter 4 with the equation: $y_{0}+a /(1+\exp (-(x-$ $\left.\left.\left.x_{0}\right) / b\right)\right)$.

(Figure 7a). The NOESY (Figure 7b) and total correlation spectroscopy (TOCSY) (Figure 7c) were used to confirm that the human lysozyme analyzed from another source in a former study ${ }^{14}$ and the human lysozyme extracted from the milk of transgenic cow do not differ from each other. With these data, it is now possible to discuss the intermolecular interaction dynamics for various insulins and lysozymes in detail.

An overlay of the 1D NMR spectrum glargine insulin Lantus (blue) with that of Glaritus (red) confirms the detected differences over the whole spectral range (Figure S1). An overlay of the two-dimensional (2D) NMR spectra of the glargine insulin Lantus (blue) with the glargine insulin Glaritus (red) shows differences, which concern the Asn 18 residue in a certain spectral region (Figure S2). Furthermore, an extra peak has been detected in the case of the glargine insulin Glaritus (red) (Figure S2). It has to be emphasized here that the corresponding ligand-receptor complex does not show any involvement of Asn18 in receptor binding (Figure S3). Therefore, any potential modification at this position (e.g., glycosylation) will not have a significant impact on receptor binding.

The 1D NMR spectrum of the porcine insulin Caninsulin (MSD), which is presented in Figure S4, is a medication used for diabetes treatment in dogs. The amino acid sequence of Caninsulin is identical to pig (porcine) insulin. The Thr residue at position 30 in the $\mathrm{B}$-chain is replaced by $\mathrm{Ala}$ in porcine insulin in comparison to human insulin. The sharp signals point to monomeric states of this insulin in the NMR tube.

Molecular Modeling Supported NMR Analyses of HL and HEWL Lysozymes in Comparison to Insulins. Owing to the complexity and robustness of nanoparticle delivery systems of protein drugs, it is essential to consider the complementarity of experimental and modeling data in the development of optimal encapsulation strategies. We combined at first the experimental and molecular modeling data that were obtained for lysozyme (HL and HEWL) (Figure $8 \mathrm{a}-\mathrm{f}$ ) and then compared them with the corresponding experimental and theoretical data gained for insulins (Figure $9 \mathrm{a}-\mathrm{e}$ ). The relation between $\mathrm{pH}$ values and lysozyme (HL and HEWL) structures is indicated by the overlay presentations shown in Figure 8c,d. When human lysozyme is encapsulated in nanoparticles for a therapeutic use, precise knowledge of the submolecular details 


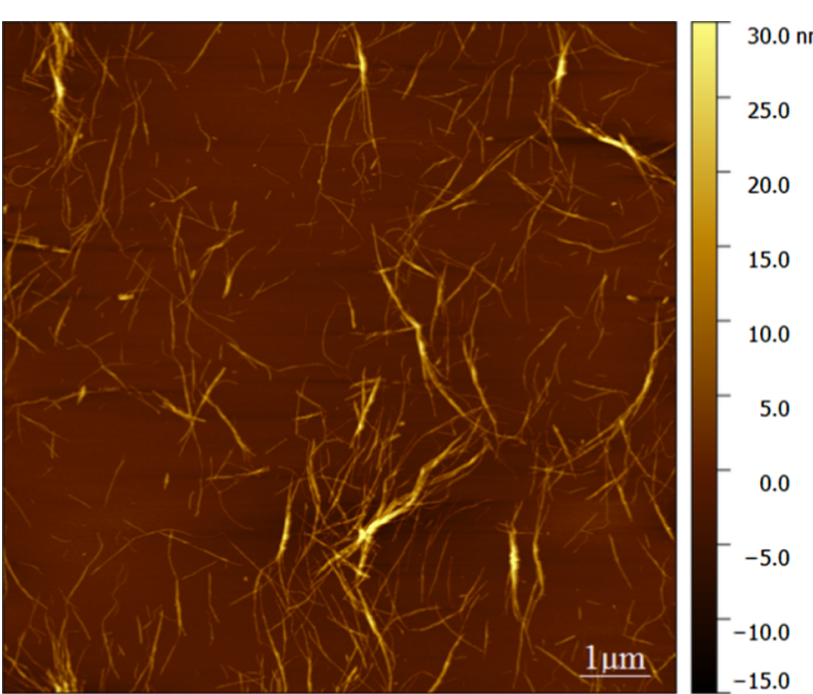

(a)

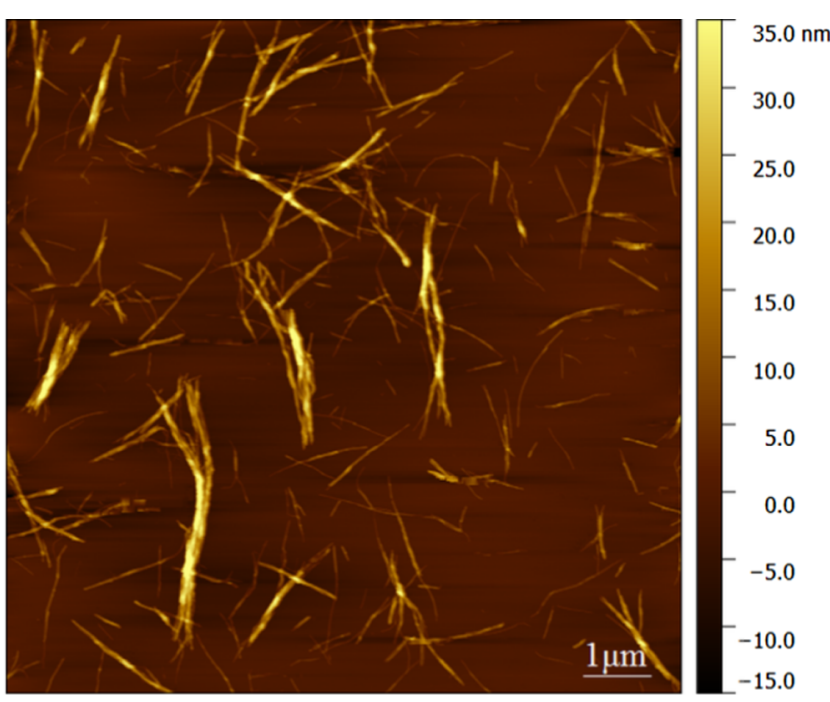

(b)

Figure 5. AFM images of $10 \mu \mathrm{M}$ glargine insulin Basalog (a) and human insulin (b) after $2 \mathrm{~h}$ incubation at $65^{\circ} \mathrm{C}$ with constant stirring (1200 rpm).

about its carbohydrate affinity ${ }^{14}$ is of importance because this part of the molecule can be considered as a vital target unit. Three essential amino acids-Tyr63 (yellow), Arg98 (red), and Trp109 (blue) - are stabilizing the complex (5lsh.pdb), highlighted in Figure 8e. The surface presentation of the same complex shown in Figure $8 \mathrm{f}$ visualizes the shape of the carbohydrate recognition part of human lysozyme. The human lysozyme (Figure 8a-f) and insulin (Figure 9a-e) data are valuable references when $\mathrm{MD}$ simulations in micelles are considered and were performed for nanoparticles as indicated in Figure 10. The surface presentations of the glargine insulin Lantus (Figure 9a, monomer) and the porcine insulin Caninsulin (Figure 9b, monomer) including their electrostatic surface potentials can be compared with each other and taken as starting structures in our MD simulations. It is necessary to correlate the data sets describing dimeric forms of human insulin (3w7y.pdb, 1mso.pdb) and porcine insulin (3fhp.pdb) as presented in Figure $9 c-e$ illustrating structural data of lysozymes.

Encapsulation of insulin into adequately sized liposome nanoparticles could facilitate optimal oral delivery of insulin while eliminating possible fibrillation processes in tissue around the injection areas. In silico methodologies were utilized to assess the nanoparticle size-insulin saturation relationships. Several differently sized liposome nanoparticles with diameters from around $35 \mathrm{~nm}$ up to approaching $120 \mathrm{~nm}$ were constructed using the PACKMOL ${ }^{37}$ program. The number of non-hydrogen atoms of insulin needed for molecular dynamics (MD) simulations can be decreased by three quarters when employing the coarse-grained (CG) approach/representation of atoms. Several observations employing different-level CG modeling (both Monte Carlo and MD simulations) for insulins and lysozymes ${ }^{38-47}$ were published recently. The total number of CG atoms in our case of glargine insulin is reduced to 95 . Consequently, hundreds of insulin molecules can be easily modeled and encapsulated into differently sized liposomal nanoparticles. Figure 10 represents nine such models sized from 35 to $120 \mathrm{~nm}$.

The structure of the $65 \mathrm{~nm}$ liposomal nanoparticle with embedded glargine insulins, as shown in Figure 11, was generated using the $\mathrm{PACKMOL}^{37}$ program. All-atom approach for insulins was used in original building step, as seen in Figure $11 \mathrm{c}, \mathrm{d}$. In the geometry-optimized spherical model, as seen from the highlighted insulin-insulin intermolecular distance, the molecules are far away from each other to allow aggregation. The lipid molecules (CG models of dipalmitoylphosphatidylcholine (DPPC) and dilauroylphosphatidylcholine (DLPC) used in this particular model; Figure 11e and 11f), restrict the motion of the insulins reducing thus their possibility to aggregate. As expected, specific intermolecular interaction processes are also dependent on certain ions in the protein environment. Figure 11a shows the ribbon presentation of porcine insulin in the presence of a trimethylamine $\mathrm{N}$-oxide molecule (similar to the Abasaglar formulation of glargine insulin) based on the X-ray structure $3 \mathrm{t} 2 \mathrm{a} . \mathrm{pdb}$. Figure $11 \mathrm{~b}$ displays the same presentation of an X-ray structure of porcine insulin without the trimethylamine $\mathrm{N}$-oxide (4a7e.pdb).

The combined molecular analysis methodologies, presented and applied here as the inaugural part for drug encapsulation strategy, have wide application options in addition to our tests on lysozyme and insulin. The strategy could also be applied for example to antimicrobial defensins and neuraminidases in cancer therapy. In any case, it is essential that the nanoparticles have a target function with respect to contact structures on the corresponding cell surfaces. The MARCKS-ED peptide with its polysialic acid affinity ${ }^{28}$ is a good candidate to become a suitable targeting peptide on the nanoparticle surface. The data presented in this publication have to be considered as essential information for better understanding of the submolecular interactions in relation to the aggregation dynamics of protein drugs. Encapsulation into liposome nanoparticles could improve the delivery strategies for these therapeutics. The molecular surface properties of the protein drugs were studied with a combination of biophysical and biochemical methods including sophisticated analytical techniques and newly developed concepts. $^{49-54}$ Large-scale production of insulin ${ }^{53}$ and the status quo of opportunities of insulin treatment ${ }^{53}$ as described in the corresponding articles might initialize the distinct need for better understanding of the aggregation behavior of insulins (human, porcine, and synthetic glargine variants). This is valid 


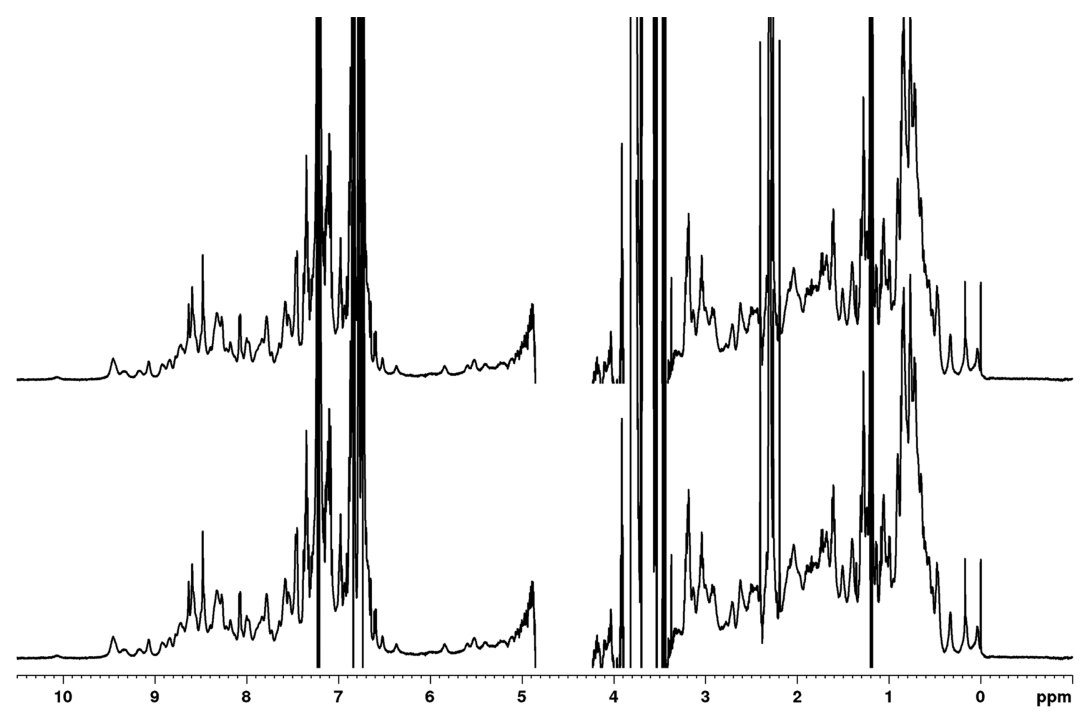

(a)

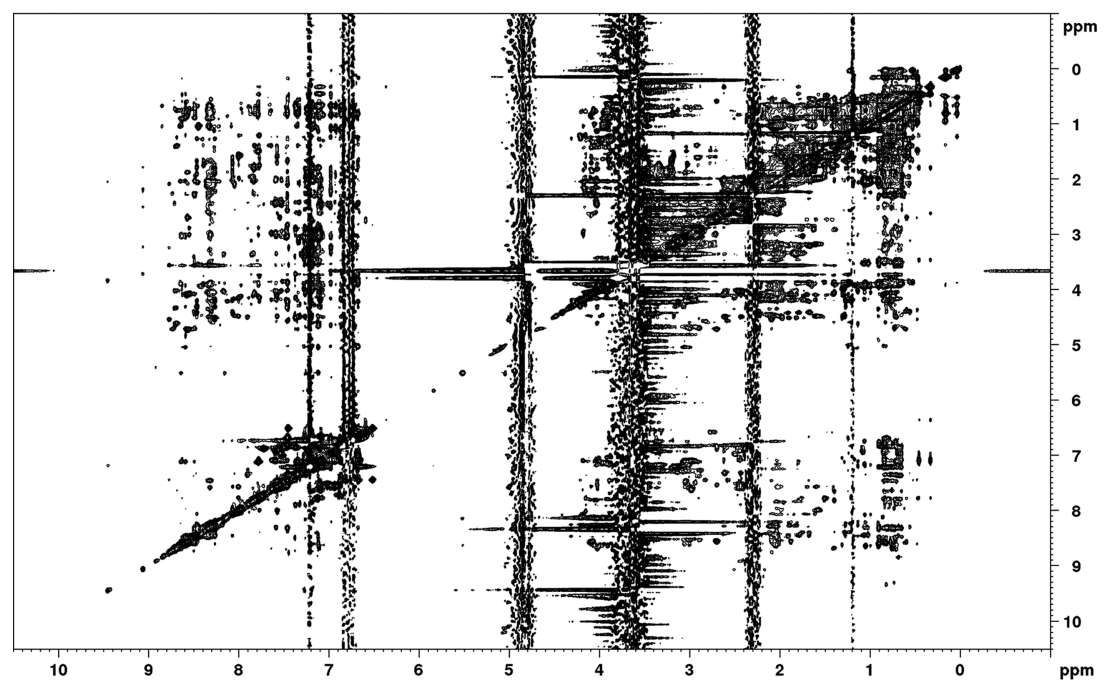

(b)

Figure 6. (a) Abasaglar glargine insulin spectra taken from different charges of insulin pens, which were stored under slightly different cooling conditions. The 1D NMR spectra of the two charges in top and bottom show identical signals. (b) NOESY NMR spectrum of the Abasaglar glargine insulin sample. Although the excipients produce strong disturbing signals, it is possible to structurally analyze the protein drug in its solution taken directly from the injection pen.

also in a similar way for lysozymes (HL and HEWL), especially specific intermolecular interactions in order to proceed toward potential applications in the framework of innovative nanomedical therapies. In the case of lysozymes, the results on specific interactions with the carbohydrate part of the LPS chains on pathogen surfaces have just been published. ${ }^{14}$ The findings with respect to an intrinsic molecular target function can be combined with the concept of targeting peptides on the surfaces of nanoparticles. When protein drugs are delivered by nanoparticles with target-directed absorption enhancers (e.g., certain collagen fragments) on their surfaces, the molecular finetuning of all components of the delivery system is the crucial step for a therapeutic success. Therefore, it is of highest importance to carefully evaluate the data concerning the structure-function relationship of the aggregation dynamics of lysozymes and insulins as described here. Certain parameters such as $\mathrm{pH}$ values, temperature, and electrostatic potentials have to be correlated with excipient and specific receptor interactions as obtained by a combination of biophysical techniques and molecular modeling methods. Consequently, the structural and physiological properties (adjusted or personalized) of insulin or lysozyme embedded into a delivery nanoparticle could be directly correlated with the functional effects in the patient's organism after their release.

\section{CONCLUSIONS}

Liposomal encapsulation for drug delivery is a significant technique as it provides an alternative to injections, and currently many research groups around the world are carrying out research ${ }^{55-57}$ to develop needle-free drug delivery 


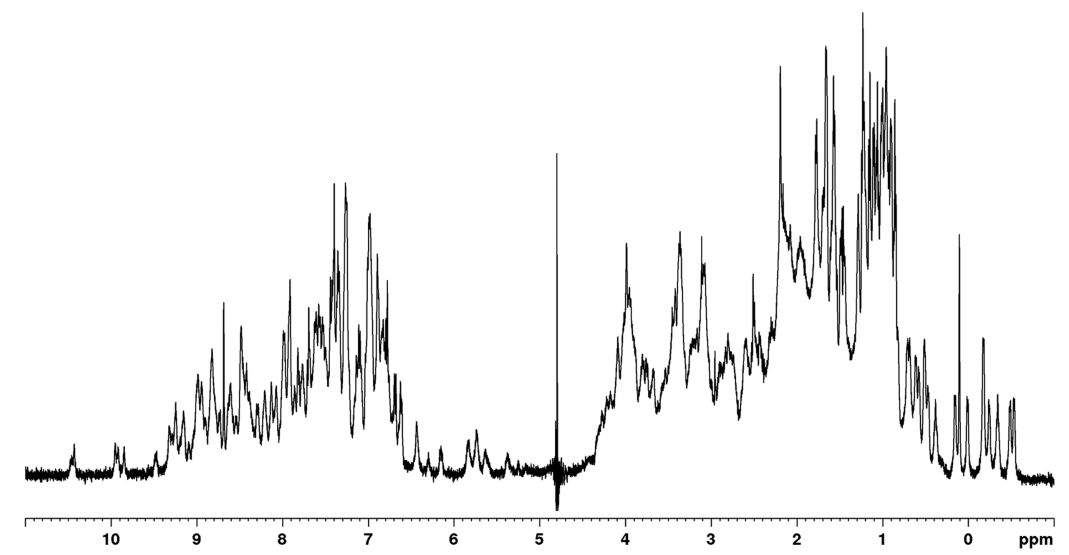

(a)

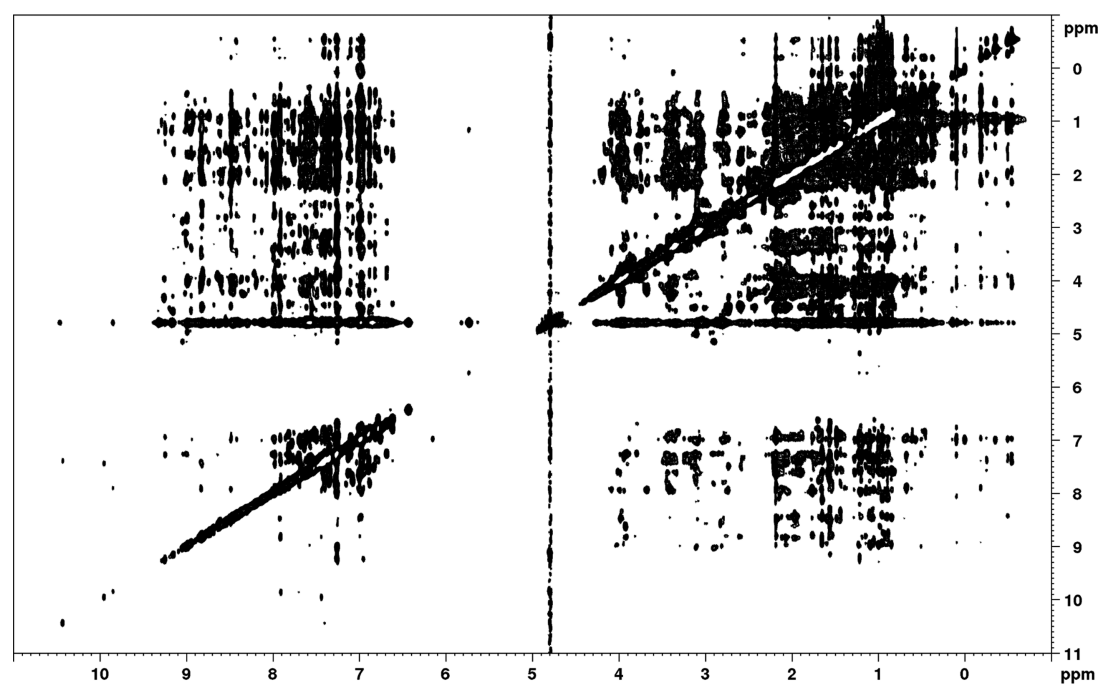

(b)

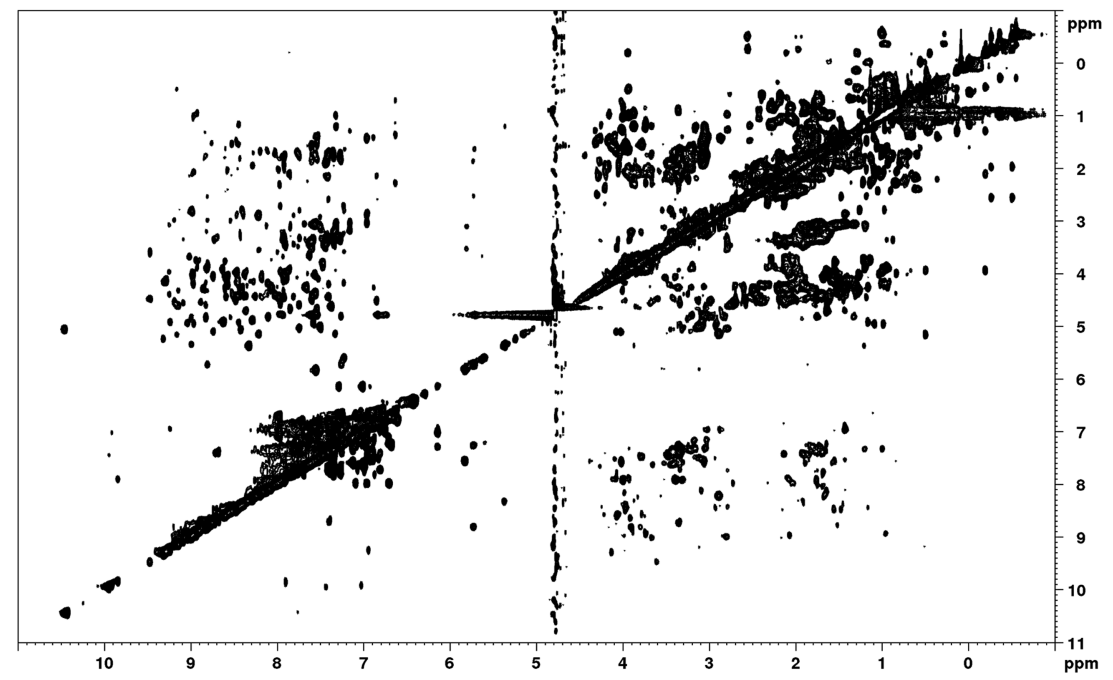

(c)

Figure 7. a) One-dimensional proton NMR spectrum of human lysozyme extracted from the milk of clone cows. The corresponding NOESY (b) and TOCSY (c) spectra are also shown. The evaluation of these spectra have led to the conclusion that no significant differences exist between the structures of the human lysozyme analyzed in a former study ${ }^{14}$ and human lysozyme extracted from the milk of clone cows.

techniques, which will improve patient compliance. The current study is focused on understanding the homo-oligomerization of the important amyloidogenic proteins lysozyme and insulin. Both are well-established amyloidogenic proteins, and both are 

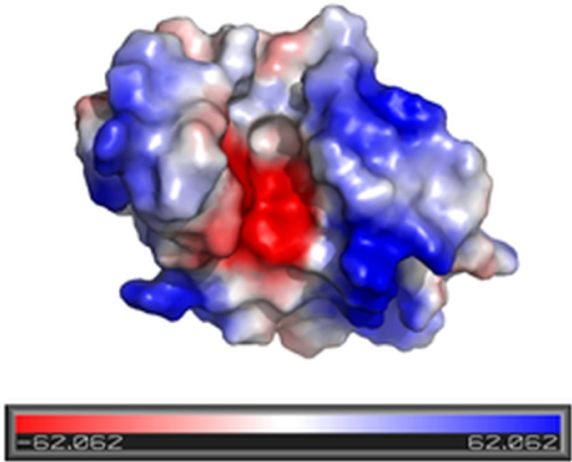

(a)
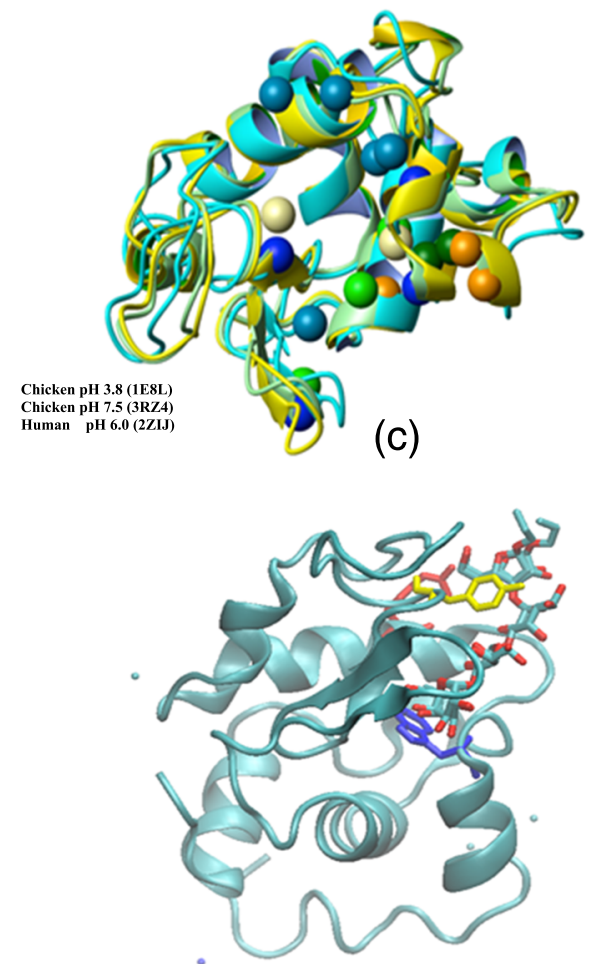

(e)
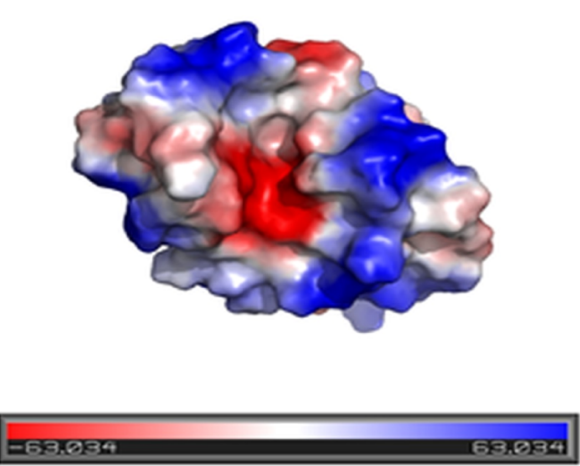

(b)

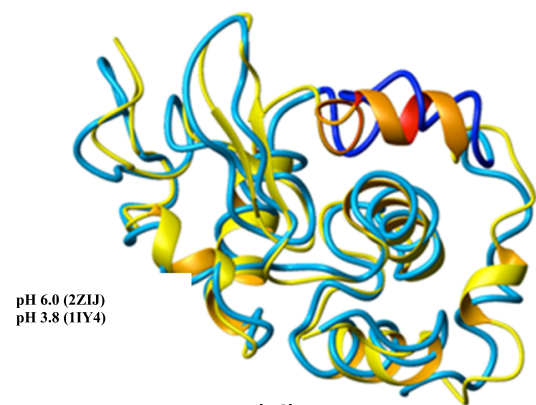

(d)

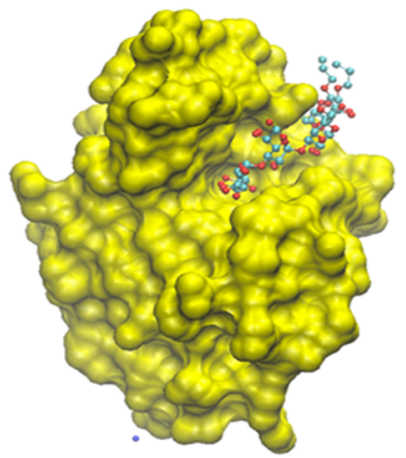

(f)

Figure 8. Surface representations of (a) HL and (b) HEWL with electrostatic surface potential. Electrostatic potentials were calculated with PyMOL. ${ }^{33}$ Red and blue colors represent the negative and positive electrostatic potentials, respectively. (c) Overlay of structures for a comparison of $\mathrm{pH}$ dependent effects in human (HL) and chicken (HEWL) lysozymes. (d) Overlay of two human lysozyme (HL) structures for a comparison of pHdependent effects. (e) Backbone and (f) surface representation of human lysozyme in complex with the tetrasaccharide O-antigen LPS fragment from K. pneumoniae (5lsh.pdb ${ }^{14}$ ). Crucial amino acids that are stabilizing the complex are highlighted on the left side by the following color code: Tyr63 (yellow), Arg98 (red), and Trp109 (blue).

therapeutic agents. Clinical cases show that insulin can form amyloid particles at the site of injection known as insulin balls. $^{58-61}$ To prevent such undesired amyloidosis, it is necessary to develop advanced drug delivery systems, ${ }^{62}$ in conjunction with insulin manufacture and treatment. ${ }^{63-65}$ Liposomal encapsulation of insulin can be a convenient alternative drug delivery strategy. The association state of the proteins is an important determinant factor of protein encapsulation into lipid-based colloidal carriers ${ }^{66}$ along with lipid-protein interaction. ${ }^{67}$ Furthermore, one needs to consider the interaction of the protein with the chosen lipid model as it is another important determinant factor, which can be studied in silico prior to wet lab experiments.

Our results show that under the different molecular environmental conditions, the association state of lysozyme and insulin varies. The variability in the molecular association governs the amyloid kinetics and the final aggregation state, as conferred from the amyloid kinetic studies of lysozyme and insulin variants. These results can help device encapsulation strategies for different lysozymes and insulins. Several other peptide-based therapeutics can be further studied as discussed in an earlier section for designing the liposomal protein encapsulation.

\section{EXPERIMENTAL SECTION}

NMR Sample Preparation. All samples were prepared by dissolving lyophilized human lysozyme (HL) or hen egg white lysozyme (HEWL) in $0.3 \mathrm{~mL}$ of $\mathrm{H}_{2} \mathrm{O}$ containing $20 \mathrm{mM}$ sodium phosphate buffer and $10 \% \mathrm{D}_{2} \mathrm{O}$. Final concentrations of all samples were $0.5 \mathrm{mM}$ protein as determined by measurement of 

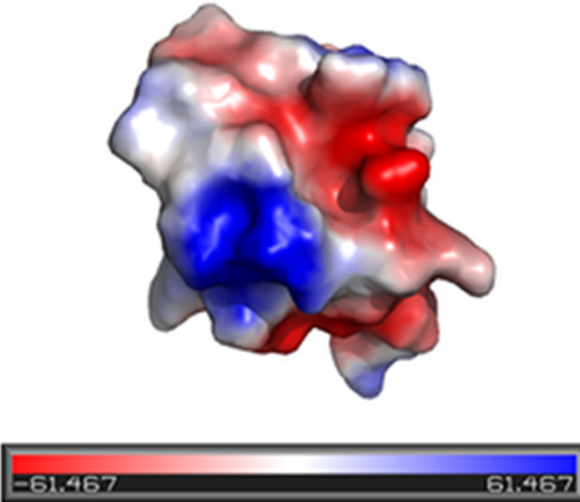

(a)
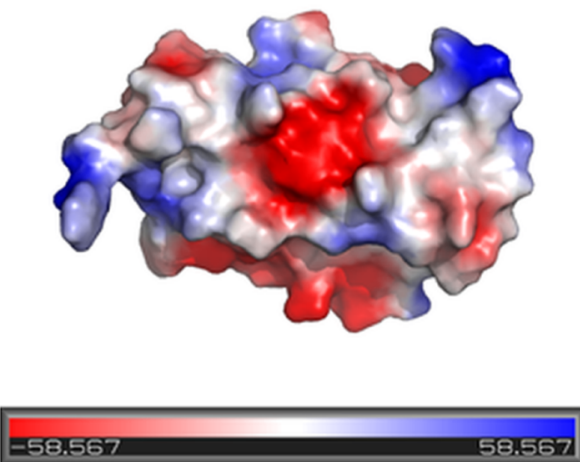

(c)
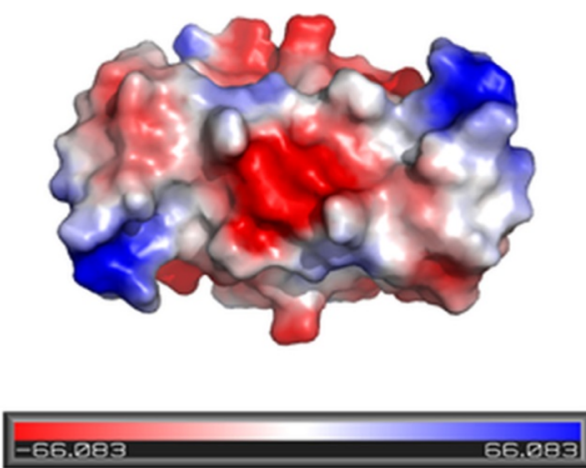

(e)
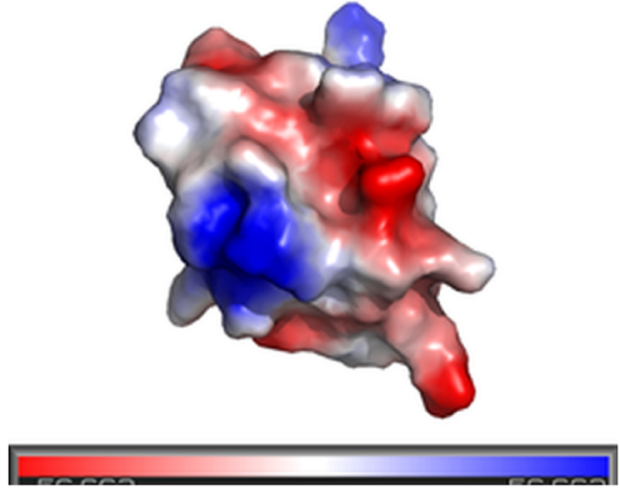

(b)

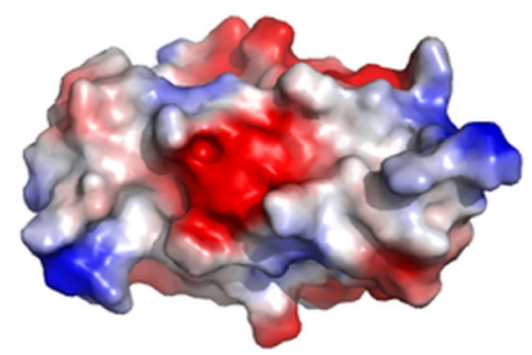

$-62.319$

(d)

Figure 9. (a) Electrostatic surface potential of the glargine insulin monomer (4iyd.pdb). (b) Electrostatic surface presentation of the porcine insulin Caninsulin monomer (3t2a.pdb). ${ }^{34}$ Surface representations of human insulin - dimeric form (c) 3 w7y.pdb and (d) $1 \mathrm{mso} . p d b^{35}$ in comparison to (e) dimeric porcine insulin $3 \mathrm{fhp} . \mathrm{pdb} .{ }^{36}$ The electrostatic potentials were calculated with PyMOL. ${ }^{33}$ Red and blue colors represent negative and positive electrostatic potentials, respectively.

the molar extinction coefficient, using E1\% $(\mathrm{w} / \mathrm{v})=25.5$ for $\mathrm{HL}$ and 26.4 for HEWL. The following samples were prepared: pure $\mathrm{HL}$ and HEWL at $\mathrm{pH} 3.8$ and 5.5, respectively. Additional samples for HL were prepared in a similar manner for the $\mathrm{pH}$ titrations described below.

NMR spectroscopy including $\mathrm{pH}$ adjustments and $\mathrm{p} K_{\mathrm{a}}$ measurements of HL: All NMR spectra were obtained using a Varian Unity INOVA $800 \mathrm{MHz}$ spectrometer at $35^{\circ} \mathrm{C}$. The $1 \mathrm{H}$ chemical shifts were referenced to 4,4-dimethyl-4-silapentane-1sulfonic acid. All experiments were run with $3 \mathrm{~mm}$ Shigemi tubes. Homonuclear two-dimensional (2D) NOESY and TOCSY (64 transients for each) with spectral width $11204 \mathrm{~Hz}$ for both dimensions were acquired with 512 increments in the indirect dimension and 4096 data points in the direct dimension using Watergate solvent suppression and a pulse sequence repetition delay of $1.5 \mathrm{~s}$. The NMRPipe ${ }^{68}$ software package was used to process all NMR data by zero-filling to 1024 points in the indirect dimension and ending with either a Gaussian or a shifted sine-bell function. The digital resolution was 0.0015 and $0.014 \mathrm{ppm}$ for the direct and indirect dimensions, respectively, after zero-filling. The following mixing times were used: $150 \mathrm{~ms}$ for the NOESYs and $50 \mathrm{~ms}$ for the TOCSYs. Ten NOESY spectra were recorded at different $\mathrm{pH}$ values between the range 3.8 and 8.1 (3.8, 4.2, 4.6, 5.0, 5.5, 6.2, 6.8, 7.4, 7.7, and 8.1) for $\mathrm{p} K_{\mathrm{a}}$ determination of HL. A separate set of HL samples was used to record $1 \mathrm{D}$ spectra at 22 different $\mathrm{pH}$ conditions in between 


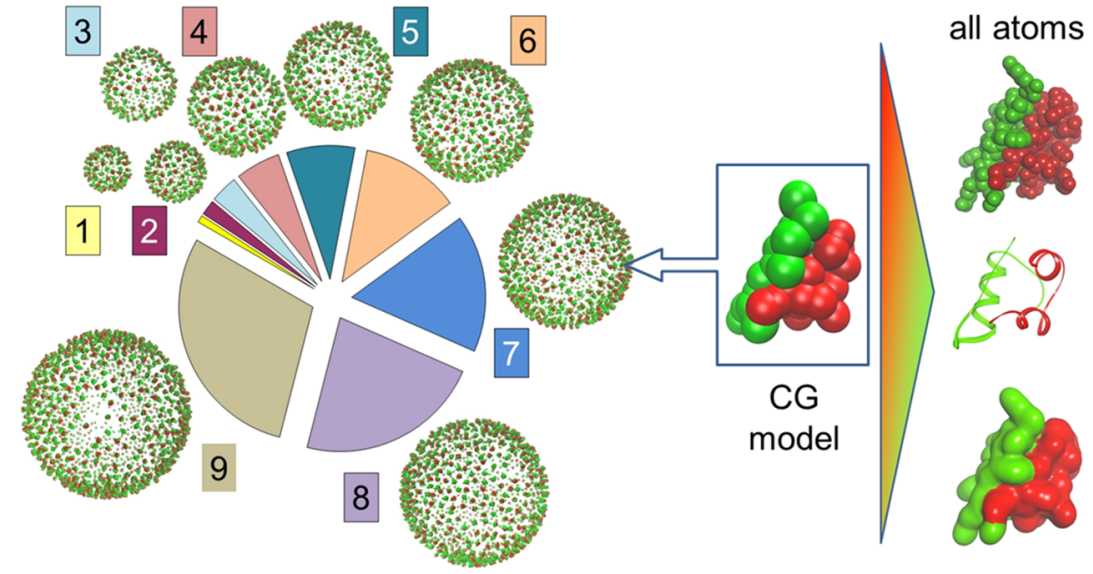

Figure 10. Structure-volume correlations of glargine insulin in "coarse-grained" (CG) presentation encapsulated into nine differently sized nanoparticles. The central pie chart illustrates the increase of the particle volumes. The insulin color coding (chain A red, chain B green) and the CG to all-atoms reverse engineering are shown in the right part of the figure (in CPK, ribbon and surface presentation). Particle sizes (radius): (1) $18 \mathrm{~nm}$; (2) $23 \mathrm{~nm}$; (3) $28 \mathrm{~nm}$; (4) $33 \mathrm{~nm}$; (5) $38 \mathrm{~nm}$; (6) $43 \mathrm{~nm}$; (7) $48 \mathrm{~nm}$; (8) $53 \mathrm{~nm}$; and (9) $58 \mathrm{~nm}$.

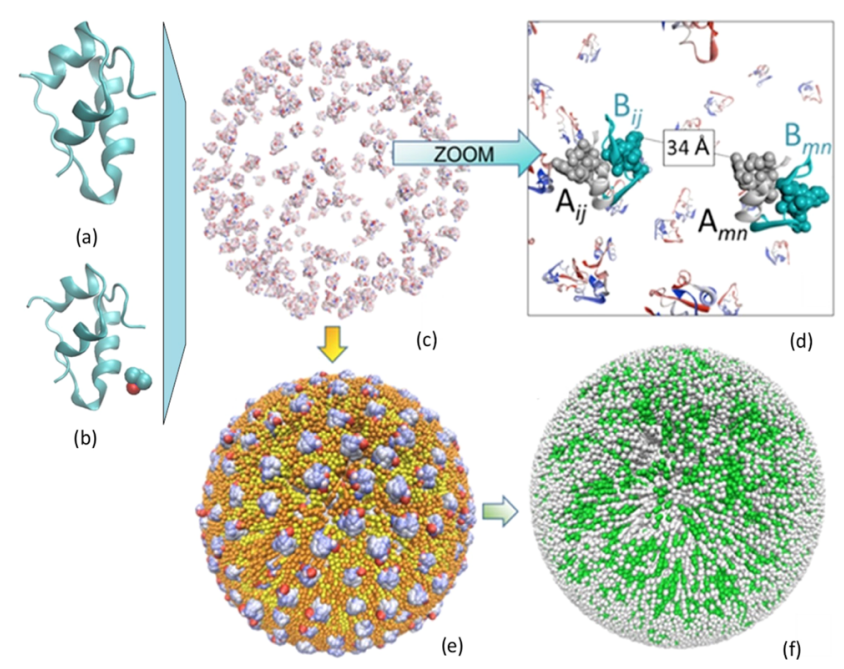

Figure 11. (a) 4a7e.pdb, porcine insulin without trimethylamine $N$ oxide; $^{48}$ (b) 3 t2a.pdb, porcine insulin with trimethylamine $\mathrm{N}$-oxide; ${ }^{34}$ (c) all-atom molecular surface representation of glargine insulins embedded into the globular $(\sim 65 \mathrm{~nm})$ nanoparticle; (d) zoomed ribbon representation of insulin with CPK highlighting of the amyloidogenic segment; (e) and (f) insulin structures (shown in allatom CPK representation) embedded into the lipid bilayer (coarsegrained modeling of DPPC and DLPC with different coloring schemes for the inner (orange and yellow) and outer (green and white) layers). The insulin molecules loaded into the liposome are protected from solvent and other environmental effects.

3.17 and 8.13 in step increment of $\sim 0.2$ units. All $1 \mathrm{D}$ data sets were defined by 4096 complex points and consisted of 256 transients. The digital resolution of the $1 \mathrm{D}$ spectra was 0.0024 ppm after zero-filling. XEASY, ${ }^{69} \mathrm{MNova}^{70}$ and $\mathrm{CCPNmr}^{71}$ were used for analysis and resonance assignment. Line widths are defined as half-width at half-height of a peak; for most peaks, the line width was estimated to be $0.01 \mathrm{ppm}$. NMR-derived models are displayed with the MOLMOL program. ${ }^{72}$

For adjusting $\mathrm{pH}$ values, either $\mathrm{H}_{3} \mathrm{PO}_{4}$ or $\mathrm{NaOH}$ was used by addition of small aliquots. The standard solutions (from Sigma) at $\mathrm{pH} 4$ and 7 were used to calibrate the $\mathrm{pH}$ meter. The temperature dependence of the $\mathrm{pH}$ reading for $\mathrm{HL}$ was checked by recalibrating the $\mathrm{pH}$ meter at $35^{\circ} \mathrm{C}$ : the difference between an incubated lysozyme sample at $35^{\circ} \mathrm{C}$ and at room temperature was less than $0.1 \mathrm{pH}$ unit. Before and after each experiment, the $\mathrm{pH}$ for each sample was measured to warrant constant conditions.

The list of excipients in Abasaglar insulin is as follows: zinc oxide, metacresol, glycerol, hydrochloric acid (for $\mathrm{pH}$ adjustment), sodium hydroxide (for $\mathrm{pH}$ adjustment), and water for injections. Therefore, strong signals from metacresol and glycerol occur in the spectra beside the protein signals.

In the case of human lysozyme, which was isolated from the milk of cloned transgenic cows, only the pure protein was extracted and therefore no disturbing signals were occurring in the corresponding spectra. ${ }^{53}$

Molecular Modeling. The structure of human lysozyme was investigated for its dimerization potential with the web server Haddock 2.2. ${ }^{73}$ For this purpose, the respective monomer proteins from 1lzs.pdb ${ }^{32}$ were used. The different proteinprotein docking results were subjected to an energy minimization with the program Hyperchem $8.0^{74}$ using the CHARMM27 force field ${ }^{75}$ in an aqueous environment. To test the stability of the dimeric proteins, an MD simulation over 10 $\mathrm{ns}$ at $298 \mathrm{~K}$ was carried out with the dimer from 1lzs.pdb, as well as with the most energetically favorable dimer from the Haddock 2.2 experiment at $\mathrm{pH}=7.4$ in physiological saline. For this, the program YASARA v.12.11.25 $5^{76}$ with the NOVA force field was used. The PyMOL ${ }^{33}$ software package was applied for visualization of the monomers and dimers.

The PACKMOL ${ }^{37}$ program was used to build the liposome structures containing the embedded insulin molecules. The combination of NAMD/VMD ${ }^{77,78}$ programs was used for further structural modeling and visualization. Coarse-grained models of modeling dilauroylphosphatidylcholine (DLPC) and modeling dipalmitoylphosphatidylcholine (DPPC) were used in liposome generation, whereas both all-atom and CG models of insulin were applied for the protein embedment. The $\mathrm{PACKMOL}^{37}$-created structures were then transformed into formats suitable for MD programs for CG simulations (GROMACS $^{79-84}$ and LAMMPS ${ }^{85}$ ) with the help of TopoTools (https://sites.google.com/site/akohlmey/software/ topotools), VMD plugin, and Moltemplate (https://www. moltemplate.org/). The Martini force field ${ }^{86-88}$ was used for CG simulations. Finally, the OVITO ${ }^{89}$ program was used for structure control and trajectory analysis. 
X-ray Crystallography. The crystallization and structure determination of human lysozyme were performed as described previously. ${ }^{14}$ In brief, human lysozyme crystals were obtained at $18^{\circ} \mathrm{C}$ using the hanging drop vapor diffusion method. Crystals were grown in $0.8 \mathrm{M} \mathrm{NaCl}, 25 \mathrm{mM} \mathrm{NaOAc}$ buffer ( $\mathrm{pH} 4.4$ ), 0.8 $\mathrm{M} \mathrm{NaCl}$, and $50 \mathrm{mM} \mathrm{NaCitrate} \mathrm{buffer}(\mathrm{pH} 5.8)$. All data collections were performed at $100 \mathrm{~K}$ and were processed with the XDS/XSCALE ${ }^{90}$ program package. The human lysozyme structure (PDB id: 1rex) ${ }^{91}$ was used as the search model for molecular replacement with the MOLREP program. ${ }^{92}$ The Refmac5 program as implemented in the CCP4 suite ${ }^{93,94}$ and PHENIX $^{95}$ was used for model building and refinement.

Amyloid Fibrillization of Hen and Human Lysozymes, Glargine, and Human Insulin. Hen egg white (HEWL) and human (HL) lysozyme amyloid fibrils were prepared through the incubation of $10 \mu \mathrm{M}$ lysozyme at $65^{\circ} \mathrm{C}$ with constant stirring (1200 rpm) in $70 \mathrm{mM}$ glycine buffer containing $80 \mathrm{mM} \mathrm{NaCl}$, $\mathrm{pH}$ 2.7. Human and glargine insulin solutions at $10 \mu \mathrm{M}$ final concentration prepared in $100 \mathrm{mM} \mathrm{NaCl}-\mathrm{HCl}$ buffer, $\mathrm{pH} 1.6$, were incubated at $65{ }^{\circ} \mathrm{C}, 1200 \mathrm{rpm}$ for $2 \mathrm{~h}$. To study kinetics of fibrillization processes, aliquots of lysozymes/insulins were withdrawn at varying times. Formation of amyloid aggregates was observed using the ThT assay. All experiments were performed in triplicate, and the presented data represent average values with standard deviations. The data were fitted with sigmoidal curve-parameter 4 with the equation: $y_{0}+a /(1+$ $\left.\exp \left(-\left(x-x_{0}\right) / b\right)\right)$ using SigmaPlot software. The presence of lysozyme/insulin amyloid fibrils was confirmed by atomic force microscopy.

Thioflavin T Fluorescence Assay. The amyloid aggregation of lysozymes and insulins was assayed by a significant enhancement of Thioflavin $\mathrm{T}$ (ThT) fluorescence in the presence of amyloid fibrils. Thioflavin $\mathrm{T}$ was added to lysozyme/insulin samples $(10 \mu \mathrm{M})$ to a final concentration of $20 \mu \mathrm{M}$. Measurements were performed in a 96-well plate using a Synergy MX (BioTek) spectrofluorimeter. The excitation wavelength was set at $440 \mathrm{~nm}$ and the emission recorded at $485 \mathrm{~nm}$. The excitation and emission slits were adjusted to 9.0/ $9.0 \mathrm{~nm}$, and the top probe vertical offset was $6 \mathrm{~mm} .^{96-100}$

Atomic Force Microscopy. Samples were deposited by drop casting on the freshly cleaved mica surface. After 5 min adsorption, the samples were washed with ultrapure water and left to dry. The protein concentration of $10 \mu \mathrm{M}$ was used. AFM images were taken by a Scanning Probe Microscope (Veeco di Innova, Bruker AXS Inc., Madison) in a tapping mode using uncoated silicon cantilevers TESPA, unmounted with force constant $42 \mathrm{~N} / \mathrm{m}$ and nominal resonance frequency $\nu=320$ $\mathrm{kHz}$, with $\mathrm{Al}$ reflective coating (Bruker AFM Probes, Camarillo). The resolution of the image was 512 pixels per line $(512 \times 512$ pixels/image) with a scan rate of $0.5 \mathrm{kHz}$. All the images are unfiltered. ${ }^{96-100}$

\section{ASSOCIATED CONTENT}

\section{S Supporting Information}

The Supporting Information is available free of charge on the ACS Publications website at DOI: 10.1021/acsomega.8b02471.

Overlay of one-dimensional NMR spectra of the glargine insulin Lantus and glargine insulin Glaritus (Figure S1); overlay of crucial parts of glargine insulin 2D NMRspectra (Figure S2); complex of human insulin with its receptor (Figure S3); 1D NMR-spectrum of Caninsulin (Figure S4) (PDF)

\section{AUTHOR INFORMATION}

\section{Corresponding Author}

*E-mail: hcsiebert@aol.com.

ORCID $\odot$

Anirban Bhunia: 0000-0002-8752-2842

Zuzana Gazova: 0000-0002-0670-3431

Nikolay E. Nifantiev: 0000-0002-0727-4050

Notes

The authors declare no competing financial interest.

\section{ACKNOWLEDGMENTS}

This work was supported by the Open Project of Shandong Collaborative Innovation Center for Antibody Drugs (No. CICAD1834) and Tai-Shan Scholar Research Fund of Shandong Province of China. This work was also technically supported by Engineering Research Center for Nanomedicine and Drug Delivery Systems. The Swedish NMR Centre is acknowledged for supplying instrument time and support. This work was supported by the King Abdullah University of Science and Technology (grant KUK-11-008-23 awarded to B.N. with Ph.D. position for L.W.) and the European Research Council (ERC2008-AdG 227700 to B.N.). We thank the Sialic Acids Society for financial support. Parts of the work were supported by RSF grant 14-23-00199 (NEN). On the Slovak side, the work was supported by project VEGA 2/0145/17, 2/0030/18, and SASMOST JRP 2015/5. This work was partly supported by Council of Scientific and Industrial Research (CSIR), Govt. of India (02(0292)/17/EMR-II) (to AB). Supports from EU projects 26220120033, 26210120002, 26110230097, and 26210120012 (IEP SAS Kosice, Slovakia) are gratefully acknowledged. We also thank Prof. Dr Frank D Sönnichsen (Otto Diels Institute for Organic Chemistry, Christian Albrechts University, Kiel, Germany) for his helpful support with respect to some of our NMR experiments. Last but not least, Dr Anna Kozarova (University of Windsor, Windsor, Ontario, Canada) is highly acknowledged for critical reading and helpful comments on the manuscript.

\section{REFERENCES}

(1) Teneback, C. C.; Scanlon, T. C.; Wargo, M. J.; Bement, J. L.; Griswold, K. E.; Leclair, L. W. Bioengineered lysozyme reduces bacterial burden and inflammation in a murine model of mucoid Pseudomonas aeruginosa lung infection. Antimicrob. Agents Chemother. 2013, 57, 5559-5564.

(2) Markart, P.; Korfhagen, T. R.; Weaver, T. E.; Akinbi, H. T. Mouse lysozyme $\mathrm{M}$ is important in pulmonary host defense against Klebsiella pneumoniae infection. Am. J. Respir. Crit. Care Med. 2004, 169, 454458.

(3) Akinbi, H. T.; Epaud, R.; Bhatt, H.; Weaver, T. E. Bacterial killing is enhanced by expression of lysozyme in the lungs of transgenic mice. J. Immunol. 2000, 165, 5760-5766.

(4) Heinemann, L.; Hompesch, M. Biosimilar insulins: how similar is similar? J. Diabetes Sci. Technol. 2011, 5, 741-754.

(5) DeVries, J. H.; Gough, S. C.; Kiljanski, J.; Heinemann, L. Biosimilar insulins: a European perspective. Diabetes, Obes. Metab. 2015, 17, 445-451.

(6) Beran, D.; Ewen, M.; Laing, R. Constraints and challenges in access to insulin: a global perspective. Lancet Diabetes Endocrinol. 2016, $4,275-285$

(7) Gong, H.; He, Z.; Peng, A.; Zhang, X.; Cheng, B.; Sun, Y.; Zheng, L.; Huang, K. Effects of several quinones on insulin aggregation. Sci. Rep. 2015, 4, No. 5648. 
(8) Owens, D. R.; Landgraf, W.; Schmidt, A.; Bretzel, R. G.; Kuhlmann, M. K. The emergence of biosimilar insulin preparations-a cause for concern? Diabetes Technol. Ther. 2012, 14, 989-996.

(9) Jelkmann, W. Molecular biology of erythropoietin. Intern. Med. 2004, 43, 649-659.

(10) Hermanns, N.; Kulzer, B.; Kohlmann, T.; Jacob, S.; Landgraf, W.; Theobald, K.; Haak, T. Treatment satisfaction and quality-of-life between type 2 diabetes patients initiating long-vs intermediate-acting basal insulin therapy in combination with oral hypoglycemic agents-a randomized, prospective, crossover, open clinical trial. Health Qual. Life Outcomes 2015, 13, No. 77.

(11) Brems, D. N.; Alter, L. A.; Beckage, M. J.; Chance, R. E.; DiMarchi, R. D.; Green, L. K.; Long, H. B.; Pekar, A. H.; Shields, J. E.; Frank, B. H. Altering the association properties of insulin by amino acid replacement. Protein Eng., Des. Sel. 1992, 5, 527-533.

(12) Weiss, M. A.; Hua, Q. X.; Lynch, C. S.; Frank, B. H.; Shoelson, S. E. Heteronuclear 2D NMR studies of an engineered insulin monomer: assignment and characterization of the receptor-binding surface by selective deuterium and carbon-13 labeling with application to protein design. Biochemistry 1991, 30, 7373-7389.

(13) Swaminathan, R.; Ravi, V. K.; Kumar, S.; Kumar, M. V.; Chandra, N. Lysozyme: a model protein for amyloid research. Adv. Protein Chem. Struct. Biol. 2011, 84, 63-111.

(14) Zhang, R. Y.; Wu, L. S.; Eckert, T.; Burg-Roderfeld, M.; RojasMacias, M. A.; Lutteke, T.; Krylov, V. B.; Argunov, D. A.; Datta, A.; Markart, P.; Guenther, A.; Norden, B.; Schauer, R.; Bhunia, A.; Enani, M. A.; Billeter, M.; Scheidig, A. J.; Nifantiev, N. E.; Siebert, H. C. Lysozyme's lectin-like characteristics facilitates its immune defense function. Q. Rev. Biophys. 2017, 50, 1-12.

(15) Siposova, K.; Kozar, T.; Musatov, A. Interaction of nonionic detergents with the specific sites of lysozyme amyloidogenic region inhibition of amyloid fibrillization. Colloids Surf., B 2017, 150, 445455 .

(16) Ponikova, S.; Kubackova, J.; Bednarikova, Z.; Marek, J.; Demjen, E.; Antosova, A.; Musatov, A.; Gazova, Z. Inhibition of lysozyme amyloidogenesis by phospholipids. Focus on long-chain dimyristoylphosphocholine. Biochim. Biophys. Acta, Gen. Subj. 2017, 1861, 29342943.

(17) Siposova, K.; Sedlak, E.; Kozar, T.; Nemergut, M.; Musatov, A. Dual Effect of Non-ionic Detergent Triton X-100 on Insulin Amyloid Formation. Colloids Surf., B 2019, 173, 709-718.

(18) Siposova, K.; Kozar, T.; Huntosova, V.; Tomkova, S.; Musatov, A. Inhibition of amyloid fibril formation and disassembly of pre-formed fibrils by natural polyphenol rottlerin. Biochim. Biophys. Acta, Proteins Proteomics 2018, DOI: 10.1016/j.bbapap.2018.10.002.

(19) Zheng, Q.; Lazo, N. D. Mechanistic Studies of the Inhibition of Insulin Fibril Formation by Rosmarinic Acid. J. Phys. Chem. B 2018, $122,2323-2331$.

(20) Donabedian, P. L.; Evanoff, M.; Monge, F. A.; Whitten, D. G.; Chi, E. Y. Substituent, Charge, and Size Effects on the Fluorogenic Performance of Amyloid Ligands: A Small-Library Screening Study. ACS Omega 2017, 2, 3192-3200.

(21) Siebert, H. C.; Tajkhorshid, E.; Dabrowski, J. Barrier to rotation around the $\mathrm{C}-\mathrm{sp}(2)-\mathrm{C}-\mathrm{sp}(2)$ bond of the ketoaldehyde enol ether $\mathrm{MeC}(\mathrm{O}) \mathrm{CH}=\mathrm{CH}-\mathrm{OEt}$ as determined by $\mathrm{C}-13 \mathrm{NMR}$ and ab initio calculations. J. Phys. Chem. A 2001, 105, 8488-8494.

(22) Ogawa, N.; Kaga, M.; Endo, T.; Nagase, H.; Furuishi, T.; Yamamoto, H.; Kawashima, Y.; Ueda, H. Quetiapine free base complexed with cyclodextrins to improve solubility for parenteral use. Chem. Pharm. Bull. 2013, 61, 809-815.

(23) Mofarrah, E.; Habibi-Khorassani, S. M.; Maghsoodlou, M. T.; Shahraki, $M$. The hindered internal rotations in isomerism forms of a particular phosphorane involving 2-chloro-phenothiazine: Dynamic $1 \mathrm{H}$ NMR study. Indian J. Chem. 2015, 54, 1528-1534.

(24) Jafari, S.; Fernandez-Enright, F.; Huang, X. F. Structural contributions of antipsychotic drugs to their therapeutic profiles and metabolic side effects. J. Neurochem. 2012, 120, 371-384.
(25) Duong, A. D.; Ruan, G.; Mahajan, K.; Winter, J. O.; Wyslouzil, B. E. Scalable, semicontinuous production of micelles encapsulating nanoparticles via electrospray. Langmuir 2014, 30, 3939-3948.

(26) Prabhu, R. H.; Patravale, V. B.; Joshi, M. D. Polymeric nanoparticles for targeted treatment in oncology: current insights. Int. J. Nanomed. 2015, 10, 1001-1018.

(27) Chen, X.; Ramstrom, O.; Yan, M. Glyconanomaterials: Emerging applications in biomedical research. Nano Res. 2014, 7, 1381-1403.

(28) Zhang, R.; Loers, G.; Schachner, M.; Boelens, R.; Wienk, H.; Siebert, S.; Eckert, T.; Kraan, S.; Rojas-Macias, M. A.; Lutteke, T.; Galuska, S. P.; Scheidig, A.; Petridis, A. K.; Liang, S.; Billeter, M.; Schauer, R.; Steinmeyer, J.; Schroder, J. M.; Siebert, H. C. Molecular Basis of the Receptor Interactions of Polysialic Acid (polySia), polySia Mimetics, and Sulfated Polysaccharides. ChemMedChem 2016, 11, 990-1002.

(29) Zhang, R.; Eckert, T.; Lutteke, T.; Hanstein, S.; Scheidig, A.; Bonvin, A. M.; Nifantiev, N. E.; Kozar, T.; Schauer, R.; Enani, M. A.; Siebert, H. C. Structure-Function Relationships of Antimicrobial Peptides and Proteins with Respect to Contact Molecules on Pathogen Surfaces. Curr. Top. Med. Chem. 2015, 16, 89-98.

(30) Eckert, T.; Stötzel, S.; Burg-Roderfeld, M.; Sewing, J.; Lütteke, T.; Nifantiev, N. E.; Vliegenthart, J. F. G.; Siebert, H. C. In Silico Study on Sulfated and Non-Sulfated Carbohydrate Chains from Proteoglycans in Cnidaria and Interaction with Collagen. Open J. Phys. Chem. 2012, 2, 123-133.

(31) Bhunia, A.; Vivekanandan, S.; Eckert, T.; Burg-Roderfeld, M.; Wechselberger, R.; Romanuka, J.; Bachle, D.; Kornilov, A. V.; von der Lieth, C. W.; Jimenez-Barbero, J.; Nifantiev, N. E.; Schachner, M.; Sewald, N.; Lutteke, T.; Siebert, H. C. Why Structurally Different Cyclic Peptides Can Be Glycomimetics of the HNK-1 Carbohydrate Antigen. J. Am. Chem. Soc. 2010, 132, 96-105.

(32) Song, H.; Inaka, K.; Maenaka, K.; Matsushima, M. Structural changes of active site cleft and different saccharide binding modes in human lysozyme co-crystallized with hexa- $\mathrm{N}$-acetyl-chitohexaose at $\mathrm{pH}$ 4.0. J. Mol. Biol. 1994, 244, 522-540.

(33) DeLano, W. L. The PyMOL Molecular Graphics System, 2002.

(34) Marshall, H.; Venkat, M.; Seng, N. S.; Cahn, J.; Juers, D. H. The use of trimethylamine $\mathrm{N}$-oxide as a primary precipitating agent and related methylamine osmolytes as cryoprotective agents for macromolecular crystallography. Acta Crystallogr., Sect. D: Biol. Crystallogr. 2012, 68, 69-81.

(35) Smith, G. D.; Pangborn, W. A.; Blessing, R. H. The structure of T6human insulin at $1.0 \AA$ resolution. Acta Crystallogr., Sect. D: Biol. Crystallogr. 2003, 59, 474-482.

(36) Iwai, W.; Yamada, T.; Kurihara, K.; Ohnishi, Y.; Kobayashi, Y.; Tanaka, I.; Takahashi, H.; Kuroki, R.; Tamada, T.; Niimura, N. A neutron crystallographic analysis of T6 porcine insulin at $2.1 \mathrm{~A}$ resolution. Acta Crystallogr., Sect. D: Biol. Crystallogr. 2009, 65, 10421050.

(37) Martínez, L.; Andrade, R.; Birgin, E. G.; Martinez, J. M. PACKMOL: a package for building initial configurations for molecular dynamics simulations. J. Comput. Chem. 2009, 30, 2157-2164.

(38) Li, J.; Chu, M. K.; Lu, B.; Mirzaie, S.; Chen, K.; Gordijo, C. R.; Plettenburg, O.; Giacca, A.; Wu, X. Y. Enhancing thermal stability of a highly concentrated insulin formulation with Pluronic F-127 for longterm use in microfabricated implantable devices. Drug Delivery Transl. Res. 2017, 7, 529-543.

(39) Carlsson, F.; Malmsten, M.; Linse, P. Monte Carlo Simulations of Lysozyme Self-Association in Aqueous Solution. J. Phys. Chem. B 2001, $105,12189-12195$.

(40) Abramo, M. C.; Caccamo, C.; Costa, D.; Pellicane, G.; Ruberto, R. Molecular dynamics of an embedded-charge model of lysozyme aqueous solutions. J. Phys. Chem. B 2010, 114, 9109-9118.

(41) Abramo, M. C.; Caccamo, C.; Calvo, M.; Conti Nibali, V.; Costa, D.; Giordano, R.; Pellicane, G.; Ruberto, R.; Wanderlingh, U. Molecular dynamics and small-angle neutron scattering of lysozyme aqueous solutions. Philos. Mag. 2011, 91, 2066-2076.

(42) Zhang, L.; Bai, S.; Sun, Y. Modification of Martini force field for molecular dynamics simulation of hydrophobic charge induction 
chromatography of lysozyme. J. Mol. Graphics Modell. 2011, 29, 906914.

(43) Abramo, M. C.; Caccamo, C.; Costa, D.; Pellicane, G.; Ruberto, R.; Wanderlingh, U. Effective interactions in lysozyme aqueous solutions: a small-angle neutron scattering and computer simulation study. J. Chem. Phys. 2012, 136, No. 035103.

(44) Zheng, W.; Glenn, P. Probing the folded state and mechanical unfolding pathways of T4 lysozyme using all-atom and coarse-grained molecular simulation. J. Chem. Phys. 2015, 142, No. 035101.

(45) Yu, G.; Zhou, J. Understanding the curvature effect of silica nanoparticles on lysozyme adsorption orientation and conformation: a mesoscopic coarse-grained simulation study. Phys. Chem. Chem. Phys. 2016, 18, 23500-23507.

(46) Wizert, A.; Iskander, D. R.; Cwiklik, L. Interaction of lysozyme with a tear film lipid layer model: A molecular dynamics simulation study. Biochim. Biophys. Acta, Biomembr. 2017, 1859, 2289-2296.

(47) Singh, A. K.; Burada, P. S.; Bhattacharya, S.; Bag, S.; Bhattacharya, A.; Dasgupta, S.; Roy, A. Microwave-radiation-induced molecular structural rearrangement of hen egg-white lysozyme. Phys. Rev. E 2018, 97, No. 052416.

(48) Burkhardt, A.; Warmer, M.; Panneerselvam, S.; Wagner, A.; Zouni, A.; Glockner, C.; Reimer, R.; Hohenberg, H.; Meents, A. Fast high-pressure freezing of protein crystals in their mother liquor. Acta Crystallogr., Sect. F: Struct. Biol. Cryst. Commun. 2012, 68, 495-500.

(49) Siebert, H. C.; Burg-Roderfeld, M.; Eckert, T.; Stotzel, S.; Kirch, U.; Diercks, T.; Humphries, M. J.; Frank, M.; Wechselberger, R.; Tajkhorshid, E.; Oesser, S. Interaction of the alpha2A domain of integrin with small collagen fragments. Protein Cell 2010, 1, 393-405.

(50) Stötzel, S.; Schurink, M.; Wienk, H.; Siebler, U.; Burg-Roderfeld, M.; Eckert, T.; Kulik, B.; Wechselberger, R.; Sewing, J.; Steinmeyer, J.; Oesser, S.; Boelens, R.; Siebert, H. C. Molecular organization of various collagen fragments as revealed by atomic force microscopy and diffusion-ordered NMR spectroscopy. ChemPhysChem 2012, 13, $3117-3125$.

(51) Schadow, S.; Siebert, H. C.; Lochnit, G.; Kordelle, J.; Rickert, M.; Steinmeyer, J. Collagen Metabolism of Human Osteoarthritic Articular Cartilage as Modulated by Bovine Collagen Hydrolysates. PLoS One 2013, 8, No. e53955.

(52) Schadow, S.; Simons, V. S.; Lochnit, G.; Kordelle, J.; Gazova, Z.; Siebert, H. C.; Steinmeyer, J. Metabolic Response of Human Osteoarthritic Cartilage to Biochemically Characterized Collagen Hydrolysates. Int. J. Mol. Sci. 2017, 18, No. 207.

(53) Lu, D.; Liu, S.; Ding, F.; Wang, H.; Li, J.; Li, L.; Dai, Y.; Li, N. Large-scale production of functional human lysozyme from marker-free transgenic cloned cows. Sci. Rep. 2016, 6, No. 22947.

(54) Wong, C. Y.; Martinez, J.; Dass, C. R. Oral delivery of insulin for treatment of diabetes: status quo, challenges and opportunities. $J$. Pharm. Pharmacol. 2016, 68, 1093-1108.

(55) Dimov, N.; Kastner, E.; Hussain, M.; Perrie, Y.; Szita, N. Formation and purification of tailored liposomes for drug delivery using a module-based micro continuous-flow system. Sci. Rep. 2017, 7, No. 12045.

(56) Colletier, J.-P.; Chaize, B.; Winterhalter, M.; Fournier, D. Protein encapsulation in liposomes: efficiency depends on interactions between protein and phospholipid bilayer. BMC Biotechnol. 2002, No. 9.

(57) Hirai, M.; Sato, S.; Kimura, R.; Hagiwara, Y.; Kawai-Hirai, R.; Ohta, N.; Igarashi, N.; Shimizu, N. Effect of protein-encapsulation on thermal structural stability of liposome composed of glycosphingolipid/ cholesterol/phospholipid. J. Phys. Chem. B 2015, 119, 3398-3406.

(58) Nagase, T.; Katsura, Y.; Iwaki, Y.; Nemoto, K.; Sekine, H.; Miwa, K.; Oh-i, T.; Kou, K.; Iwaya, K.; Noritake, M.; Matsuoka, T. The insulin ball. Lancet 2009, 373, 184.

(59) Yumlu, S.; Barany, R.; Eriksson, M.; Rocken, C. Localized insulinderived amyloidosis in patients with diabetes mellitus: a case report. Hum. Pathol. 2009, 40, 1655-1660.

(60) Kudo-Watanuki, S.; Kurihara, E.; Yamamoto, K.; Mukai, K.; Chen, K. R. Coexistence of insulin-derived amyloidosis and an overlying acanthosis nigricans-like lesion at the site of insulin injection. Clin. Exp. Dermatol. 2013, 38, 25-29.
(61) Lonsdale-Eccles, A. A.; Gonda, P.; Gilbertson, J. A.; Haworth, A. E. Localized cutaneous amyloid at an insulin injection site. Clin. Exp. Dermatol. 2009, 34, e1027-e1028.

(62) Banerjee, A.; Ibsen, K.; Brown, T.; Chen, R.; Agatemor, C.; Mitragotri, S. Ionic liquids for oral insulin delivery. Proc. Natl. Acad. Sci. U. S. A. 2018, 115, 7296-7301.

(63) Walsh, G. Therapeutic insulins and their large-scale manufacture. Appl. Microbiol. Biotechnol. 2004, 67, 151-159.

(64) Davis, A.; Kuriakose, J.; Clements, J. N. Faster Insulin Aspart: A New Bolus Option for Diabetes Mellitus. Clin. Pharmacokinet. 2018, DOI: $10.1007 / \mathrm{s} 40262-018-0696-8$.

(65) Sandow, J.; Landgraf, W.; Becker, R.; Seipke, G. Equivalent Recombinant Human Insulin Preparations and their Place in Therapy. Eur. Endocrinol. 2015, 11, No. 10.

(66) Martins, S.; Sarmento, B.; Ferreira, D. C.; Souto, E. B. Lipidbased colloidal carriers for peptide and protein delivery - liposomes versus lipid nanoparticles. J. Nanomed. 2007, 2, 595-607.

(67) Ratha, B. N.; Kim, M.; Sahoo, B.; Garai, K.; Lee, D.; Bhunia, A. Insulin-eukaryotic model membrane interaction: Mechanistic insight of insulin fibrillation and membrane disruption. Biochim. Biophys. Acta 2018, 1860, 1917-1926.

(68) Delaglio, F.; Grzesiek, S.; Vuister, G. W.; Zhu, G.; Pfeifer, J.; Bax, A. NMRPipe: a multidimensional spectral processing system based on UNIX pipes. J. Biomol. NMR 1995, 6, 277-93.

(69) Bartels, C.; Xia, T. H.; Billeter, M.; Guntert, P.; Wuthrich, K. The program XEASY for computer-supported NMR spectral analysis of biological macromolecules. J. Biomol. NMR 1995, 6, 1-10.

(70) Claridge, T. Software Review of MNova: NMR Data Processing, Analysis, and Prediction Software; ACS Publications, 2009.

(71) Vranken, W. F.; Boucher, W.; Stevens, T. J.; Fogh, R. H.; Pajon, A.; Llinas, M.; Ulrich, E. L.; Markley, J. L.; Ionides, J.; Laue, E. D. The CCPN data model for NMR spectroscopy: development of a software pipeline. Proteins 2005, 59, 687-96.

(72) Koradi, R.; Billeter, M.; Wuthrich, K. MOLMOL: a program for display and analysis of macromolecular structures. J. Mol. Graph. 1996, $14,51-5$ 29-32.

(73) van Zundert, G. C. P.; Rodrigues, J.; Trellet, M.; Schmitz, C.; Kastritis, P. L.; Karaca, E.; Melquiond, A. S. J.; van Dijk, M.; de Vries, S. J.; Bonvin, A. The HADDOCK2.2 Web Server: User-Friendly Integrative Modeling of Biomolecular Complexes. J. Mol. Biol. 2016, $428,720-725$.

(74) Hyperchem, version 8.0; Hypercube, Inc.: Gainesville, FL, 2007.

(75) MacKerell, A. D.; Bashford, D.; Bellott, M.; Dunbrack, R. L.; Evanseck, J. D.; Field, M. J.; Fischer, S.; Gao, J.; Guo, H.; Ha, S.; JosephMcCarthy, D.; Kuchnir, L.; Kuczera, K.; Lau, F. T. K.; Mattos, C.; Michnick, S.; Ngo, T.; Nguyen, D. T.; Prodhom, B.; Reiher, W. E.; Roux, B.; Schlenkrich, M.; Smith, J. C.; Stote, R.; Straub, J.; Watanabe, M.; Wiorkiewicz-Kuczera, J.; Yin, D.; Karplus, M. All-atom empirical potential for molecular modeling and dynamics studies of proteins. J. Phys. Chem. B 1998, 102, 3586-3616.

(76) Krieger, E.; Koraimann, G.; Vriend, G. Increasing the precision of comparative models with YASARA NOVA-a self-parameterizing force field. Proteins 2002, 47, 393-402.

(77) Phillips, J. C.; Braun, R.; Wang, W.; Gumbart, J.; Tajkhorshid, E.; Villa, E.; Chipot, C.; Skeel, R. D.; Kale, L.; Schulten, K. Scalable molecular dynamics with NAMD. J. Comput. Chem. 2005, 26, 1781802.

(78) Humphrey, W.; Dalke, A.; Schulten, K. VMD: visual molecular dynamics. J. Mol. Graphics 1996, 14, 33-8 27-8 .

(79) Berendsen, H. J. C.; Vanderspoel, D.; Vandrunen, R. Gromacs - A Message-Passing Parallel Molecular-Dynamics Implementation. Comput. Phys. Commun. 1995, 91, 43-56.

(80) Lindahl, E.; Hess, B.; van der Spoel, D. GROMACS 3.0: a package for molecular simulation and trajectory analysis. J. Mol. Model. 2001, 7, 306-317.

(81) Van Der Spoel, D.; Lindahl, E.; Hess, B.; Groenhof, G.; Mark, A. E.; Berendsen, H. J. GROMACS: fast, flexible, and free. J. Comput. Chem. 2005, 26, 1701-18. 
(82) Hess, B.; Kutzner, C.; van der Spoel, D.; Lindahl, E. GROMACS 4: Algorithms for Highly Efficient, Load-Balanced, and Scalable Molecular Simulation. J. Chem. Theory Comput. 2008, 4, 435-47.

(83) Pronk, S.; Pall, S.; Schulz, R.; Larsson, P.; Bjelkmar, P.; Apostolov, R.; Shirts, M. R.; Smith, J. C.; Kasson, P. M.; van der Spoel, D.; Hess, B.; Lindahl, E. GROMACS 4.5: a high-throughput and highly parallel open source molecular simulation toolkit. Bioinformatics 2013, $29,845-54$.

(84) Abraham, M. J.; Murtola, T.; Schulz, R.; Páll, S.; Smith, J. C.; Hess, B.; Lindahl, E. GROMACS: High performance molecular simulations through multi-level parallelism from laptops to supercomputers. SoftwareX 2015, 1-2, 19-25.

(85) Plimpton, S. Fast Parallel Algorithms for Short-Range Molecular Dynamics. J. Comput. Phys. 1995, 117, 1-19.

(86) Marrink, S. J.; de Vries, A. H.; Mark, A. E. Coarse grained model for semiquantitative lipid simulations. J. Phys. Chem. B 2004, 108, 750760.

(87) Marrink, S. J.; Risselada, H. J.; Yefimov, S.; Tieleman, D. P.; de Vries, A. H. The MARTINI force field: Coarse grained model for biomolecular simulations. J. Phys. Chem. B 2007, 111, 7812-7824.

(88) Monticelli, L.; Kandasamy, S. K.; Periole, X.; Larson, R. G.; Tieleman, D. P.; Marrink, S. J. The MARTINI coarse-grained force field: Extension to proteins. J. Chem. Theory Comput. 2008, 4, 819-834.

(89) Stukowski, A. Visualization and analysis of atomistic simulation data with OVITO - the Open Visualization Tool. Modell. Simul. Mater. Sci. Eng. 2010, 18, No. 015012.

(90) Kabsch, W. Integration, scaling, space-group assignment and post-refinement. Acta Crystallogr., Sect. D: Biol. Crystallogr. 2010, 66, 133-144.

(91) Muraki, M.; Harata, K.; Sugita, N.; Sato, K.-i. Origin of Carbohydrate Recognition Specificity of Human Lysozyme Revealed by Affinity Labeling. Biochemistry 1996, 35, 13562-13567.

(92) Vagin, A.; Teplyakov, A. MOLREP: an Automated Program for Molecular Replacement. J. Appl. Crystallogr. 1997, 30, 1022-1025.

(93) Winn, M.; Ballard, C.; Keegan, R.; Pelios, G.; Zhao, N.; Krissinel, E. The CCP4 software suite - current status and future developments. Acta Crystallogr., Sect. A: Found. Crystallogr. 2010, 66, s127.

(94) Murshudov, G. N.; Skubák, P.; Lebedev, A. A.; Pannu, N. S.; Steiner, R. A.; Nicholls, R. A.; Winn, M. D.; Long, F.; Vagin, A. A. REFMAC5 for the refinement of macromolecular crystal structures. Acta Crystallogr., Sect. D: Biol. Crystallogr. 2011, 67, 355-367.

(95) Adams, P. D.; Afonine, P. V.; Bunkóczi, G.; Chen, V. B.; Davis, I. W.; Echols, N.; Headd, J. J.; Hung, L.-W.; Kapral, G. J.; GrosseKunstleve, R. W.; McCoy, A. J.; Moriarty, N. W.; Oeffner, R.; Read, R. J.; Richardson, D. C.; Richardson, J. S.; Terwilliger, T. C.; Zwart, P. H. PHENIX: a comprehensive Python-based system for macromolecular structure solution. Acta Crystallogr., Sect. D: Biol. Crystallogr. 2010, 66, 213-221.

(96) Antosova, A.; Chelli, B.; Bystrenova, E.; Siposova, K.; Valle, F.; Imrich, J.; Vilkova, M.; Kristian, P.; Biscarini, F.; Gazova, Z. Structureactivity relationship of acridine derivatives to amyloid aggregation of lysozyme. Biochim. Biophys. Acta, Gen. Subj. 2011, 1810, 465-74.

(97) Siposova, K.; Bystrenova, E.; Antosova, A.; Koneracka, M.; Zavisova, V.; Kopcansky, P.; Gazova, Z. Attenuation of the insulin amyloid aggregation in presence of $\mathrm{Fe} 3 \mathrm{O} 4-$ based magnetic fluids. Gen. Physiol. Biophys. 2013, 32, 209-14.

(98) Gazova, Z.; Siposova, K.; Kurin, E.; Mucaji, P.; Nagy, M. Amyloid aggregation of lysozyme: the synergy study of red wine polyphenols. Proteins 2013, 81, 994-1004.

(99) Vuong, Q. V.; Siposova, K.; Nguyen, T. T.; Antosova, A.; Balogova, L.; Drajna, L.; Imrich, J.; Li, M. S.; Gazova, Z. Binding of glyco-acridine derivatives to lysozyme leads to inhibition of amyloid fibrillization. Biomacromolecules 2013, 14, 1035-43.

(100) Viet, M. H.; Siposova, K.; Bednarikova, Z.; Antosova, A.; Nguyen, T. T.; Gazova, Z.; Li, M. S. In Silico and in Vitro Study of Binding Affinity of Tripeptides to Amyloid beta Fibrils: Implications for Alzheimer's Disease. J. Phys. Chem. B 2015, 119, 5145-55. 